\title{
PopLib Unit Test Report For HPAC Version 6.4
}

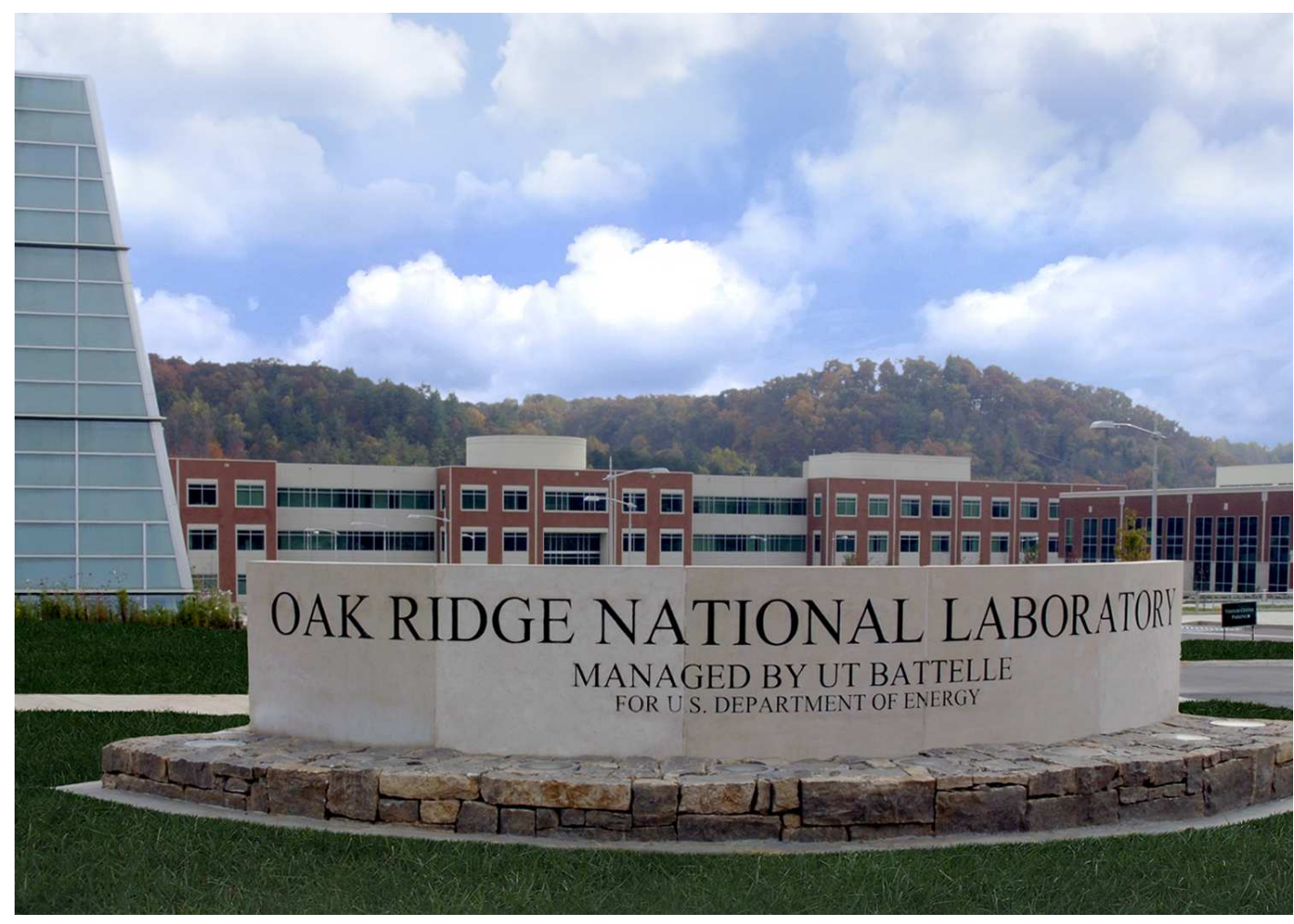

Ronald W. Lee

March, 2017

Approved for Public Release. Distribution is Unlimited. 


\section{DOCUMENT AVAILABILITY}

Reports produced after January 1, 1996, are generally available free via the U.S. Department of Energy (DOE) SciTech Connect.

Website: http://www.osti.gov/scitech

Reports produced before January 1, 1996, may be purchased by members of the public from the following source.

National Technical Information Service

5825 Port Royal Road

Springfield, VA 22161

Telephone: 703-605-6000 (1-800-553-6847)

TDD: 703-487-4639

Fax: 703-605-6900

E-mail: info@ntis.fedworld.gov

Website: http://www.ntis.gov/help/ordermethods.aspx

Reports are available to DOE employees, DOE contractors, Energy Technology Data Exchange (ETDE) representatives, and International Nuclear Information System (INIS) representatives from the following source.

Office of Scientific and Technical Information

P.O. Box 62

Oak Ridge, TN 37831

Telephone: 865-576-8401

Fax: 865-576-5728

E-mail: reports@osti.gov

Website: http://www.osti.gov/contact.html

This report was prepared as an account of work sponsored by an agency of the United States Government. Neither the United States Government nor any agency thereof, nor any of their employees, makes any warranty, express or implied, or assumes any legal liability or responsibility for the accuracy, completeness, or usefulness of any information, apparatus, product, or process disclosed, or represents that its use would not infringe privately owned rights. Reference herein to any specific commercial product, process, or service by trade name, trademark, manufacturer, or otherwise, does not necessarily constitute or imply its endorsement, recommendation, or favoring by the United States Government or any agency thereof. The views and opinions of authors expressed herein do not necessarily state or reflect those of the United States Government or any agency thereof. 
Computational Sciences and Engineering Division

\title{
POPLIB UNIT TEST REPORT FOR HPAC VERSION 6.4
}

\author{
Ronald W. Lee
}

Date Published: March, 2017

Prepared by OAK RIDGE NATIONAL LABORATORY

Oak Ridge, Tennessee 37831-6285

managed by UT-BATTELLE, LLC

for the

U.S. DEPARTMENT OF ENERGY

under contract DE-AC05-00OR22725 


\section{CONTENTS}

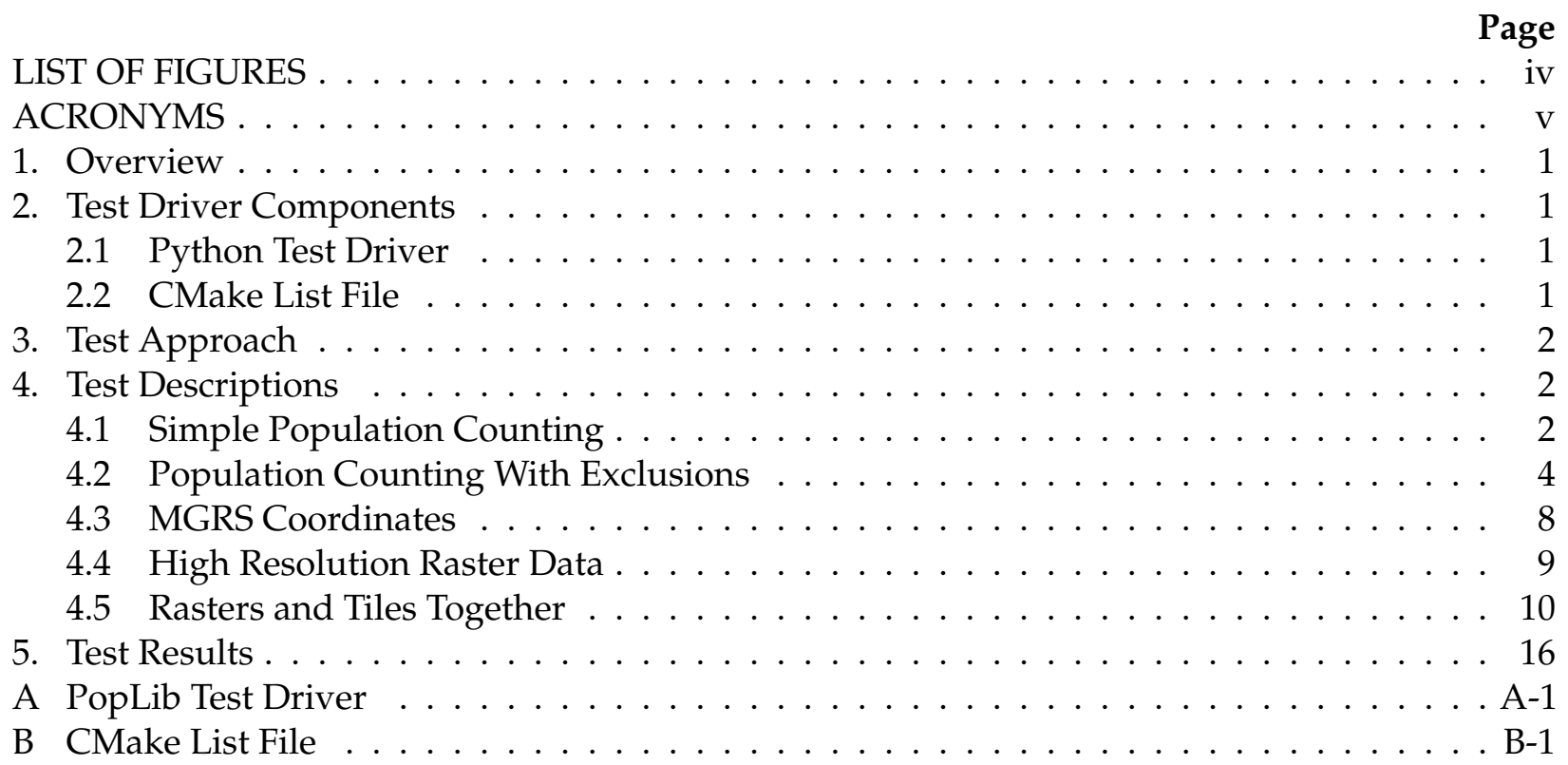




\section{LIST OF FIGURES}

\begin{tabular}{|c|c|c|}
\hline \multicolumn{2}{|c|}{ Figures } & Page \\
\hline 1 & Tests 0001 and 0002. & 3 \\
\hline 2 & Tests 0003 and 0004. & 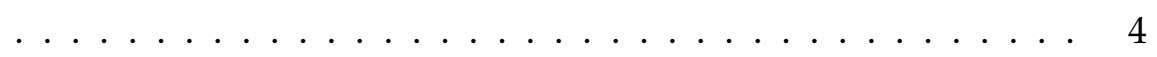 \\
\hline 3 & Tests 0005 and 0006. & $\ldots \ldots \ldots \ldots \ldots \ldots \ldots \ldots$ \\
\hline 4 & Tests 0007 and 0008. & $\ldots \ldots \ldots \ldots$ \\
\hline 5 & Tests 0033 and 0034. & 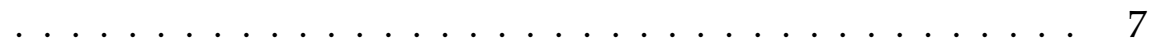 \\
\hline 6 & Tests 0009-0012. & $\ldots \ldots \ldots \ldots$ \\
\hline 7 & Tests 0013-0016. & $\ldots \ldots \ldots \ldots \ldots$ \\
\hline 8 & Tests 0035-0038. & 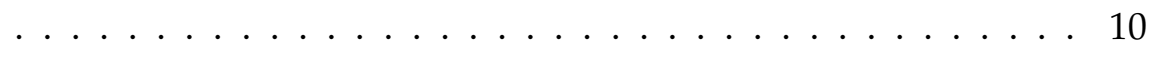 \\
\hline 9 & Test 0052 . & . 11 \\
\hline 10 & Test 0053. & $\ldots \ldots \ldots \ldots \ldots$ \\
\hline 11 & Test 0054 . & $\ldots \ldots 13$ \\
\hline 12 & Test 0055 . & ..... 14 \\
\hline 13 & Test 0056. . . & 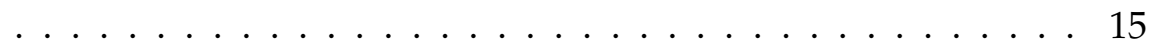 \\
\hline 14 & Test 0057. . . . & 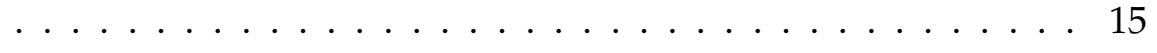 \\
\hline
\end{tabular}




\title{
ACRONYMS
}

\author{
API Application Programming Interface \\ DLL Dynamic Link Library \\ DTRA Defense Threat Reduction Agency \\ HPAC Hazard Prediction and Assessment Capability \\ MGRS Military Grid Reference System \\ SCIPUFF Second-order Closure Integrated Puff Model
}




\section{OVERVIEW}

This document describes the methodology for and results of testing the PopLib component in Version 6.4 of the Hazard Predication and Assessment Capability (HPAC). PopLib's use in HPAC is solely as a dynamic link library (DLL) called from the Second-order Closure Integrated Puff Model (SCIPUFF).

PopLib is a cross-platform capability that is built using CMake on Windows, Mac OS X, and Linux platforms. In addition to the shared object (file with .so extension under Linux and .dylib extension under Mac OS X) or dynamic link library (DLL) (Windows file with .dll extension), a command-line utility, poplib_run is also created. The utility can be used to invoke any/all PopLib capabilities with files defining polygons passed as inputs. Most PopLib unit tests execute poplib_run with results compared against baseline files.

For testing, PopLib is built under Windows using a CMake out-of-source build in a simple four-step process, with one additional step to execute the tests. The steps below assume the source directory is current at the start.

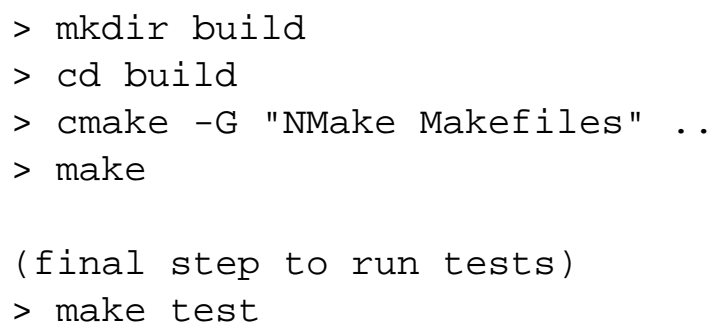

\section{TEST DRIVER COMPONENTS}

In addition to the poplib_run command-line utility, two components are needed for PopLib testing: a test driver implemented with Python-2, and a special test for Military Grid Reference System (MGRS) conversions mgrs_test.

\subsection{PYTHON TEST DRIVER}

The Python driver poplib_test_driver.py is listed in Appendix A. It takes care of executing poplib_run with the proper options and inputs and comparing test results to baselines.

\subsection{CMAKE LIST FILE}

As per CMake/CTest design, individual tests are defined in a CMake "list" file, CMakeLists.txt, listed in Appendix B. Note the compile and link of mgrs_test is also specified in this file. Three macros aid in defining tests:

- add_exclusion_test()

- add_mgrs_test()

- add_simple_test()

Generally, test definitions include specification of: 
- Population data directories to read,

- Input polygon files,

- Special options for poplib_run, and

- The allowed test timeout.

\section{TEST APPROACH}

All PopLib tests are pure unit tests that are automated and unattended, executed with CMake and CTest. ${ }^{1}$ A total of 62 tests are run upon each build of PopLib on all three target platforms. Note the same baseline files are used for all platforms. Many tests represent pairs of the same test using tile and raster data, respectively. There are also many tests that exercise the exclusion polygon capability added for HPAC-6.3, some of which include the fixed population feature added for 6.3 Patch 2. Additional tests focus on exclusion polygons defined with Military Grid Reference System (MGRS) coordinates.

Population data against which PopLib is exercised are included in the source code repository. They are arranged in directories whose names are self-explanatory:

- rasters

- levant

- mosul

- ne-usa

- rasters-only

- tiles

- levant

- ne-usa

- tiles-and-rasters

\section{TEST DESCRIPTIONS}

\subsection{SIMPLE POPULATION COUNTING}

Test0001_dc_around_tiles. This is a simple test of counting the population within a polygon using tile files. The population data and input polygon are depicted in Fig. 1.

Test0002_dc_around_rasters. Repeats Test0001 with raster population files.

Test0003_dc_inner_tiles. This is a simple test of counting the population within a polygon using tile files. The population data and input polygon are depicted in Fig. 2.

Test0004_dc_inner_rasters. Repeats Test0003 with raster population files. 


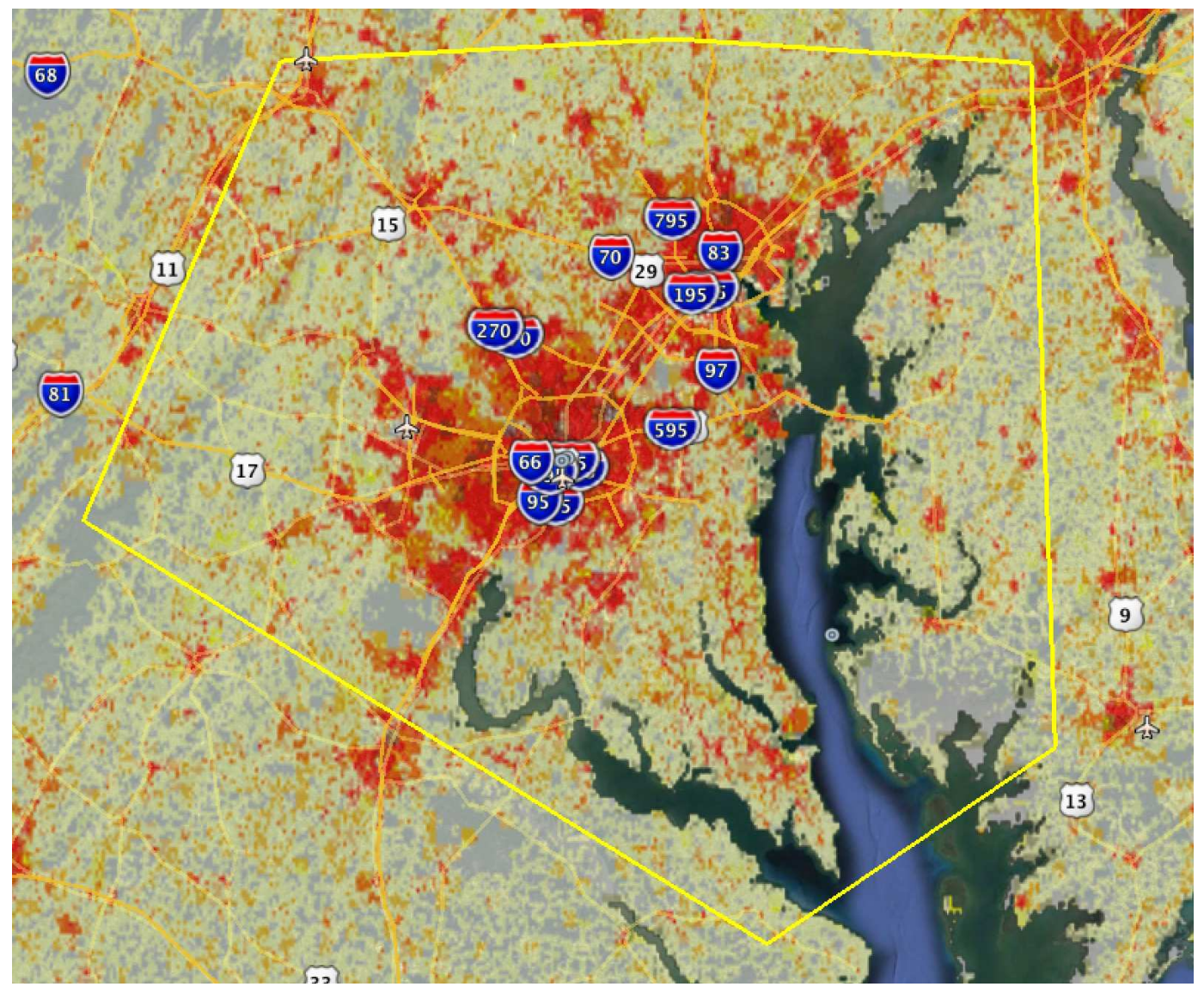

Fig. 1: Tests 0001 and 0002.

Test0005_dc_diamond_tiles. This is a simple test of counting the population within a polygon using tile files. The population data and input polygon are depicted in Fig. 3.

Test0006_dc_diamond_rasters. Repeats Test0005 with raster population files.

Test0007_ny_triangle_tiles. This is a simple test of counting the population within a polygon using tile files. The population data and input polygon are depicted in Fig. 4.

Test0008_ny_triangle_rasters. Repeats Test0007 with raster population files.

Test0033_i258_tiles. This is a simple test of counting the population within a complex polygon using tile files. The population data and input polygon (white) are depicted in Fig. 5.

Test0034_i258_rasters. Repeats Test0033 with raster population files. 


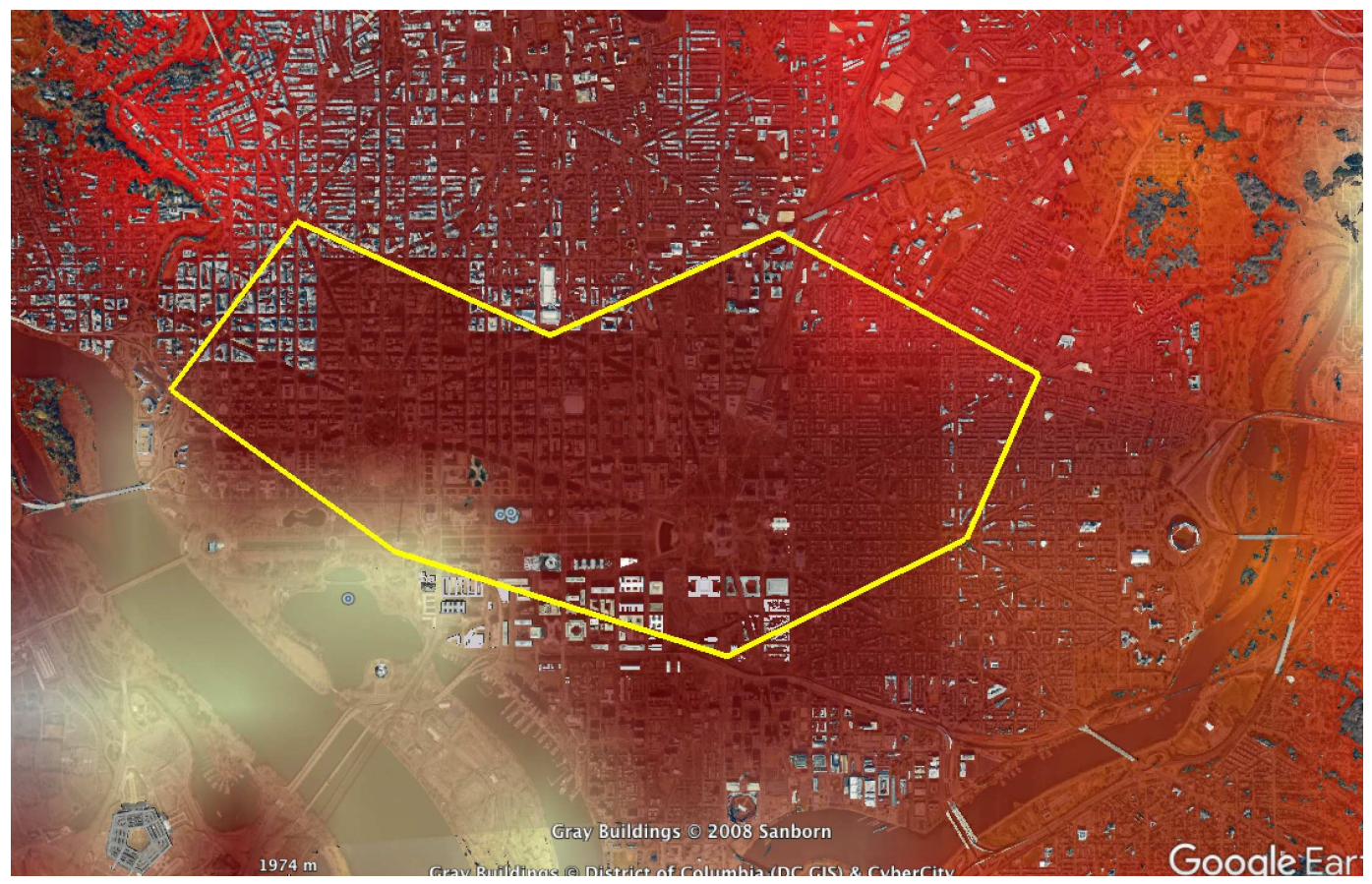

Fig. 2: Tests 0003 and 0004.

\subsection{POPULATION COUNTING WITH EXCLUSIONS}

Test0009_va_exclude_1_tiles. Tests population counting with an exclusion polygon file specified via the PopLib_exclusionFile environment variable. Population data are in tile files. The population data, input polygon (yellow), and exclusion polygon (red) are depicted in Fig. 6.

Test0010_va_exclude_1_tiles_ini. Duplicates Test0010 with the exclusion polygon specified in the ini file instead of the environment variable.

$\underline{\text { Test0011_va_exclude_1_rasters. Duplicates Test0009 with population data as rasters. }}$

Test0012_va_exclude_1_rasters_ini. Duplicates Test0010 with population data as rasters.

Test0013_va_exclude_2_tiles. Tests population counting with an exclusion polygon file specified via the PopLib_exclusionFile environment variable. Population data are in tile files. The population data, input polygon (yellow), and exclusion polygon (red) are depicted in Fig. 7.

Test0014_va_exclude_2_tiles_ini. Duplicates Test0013 with the exclusion polygon specified in the ini file instead of the environment variable.

Test0015_va_exclude_2_rasters. Duplicates Test0013 with population data as rasters.

Test0016_va_exclude_2_rasters_ini. Duplicates Test0014 with population data as rasters. 


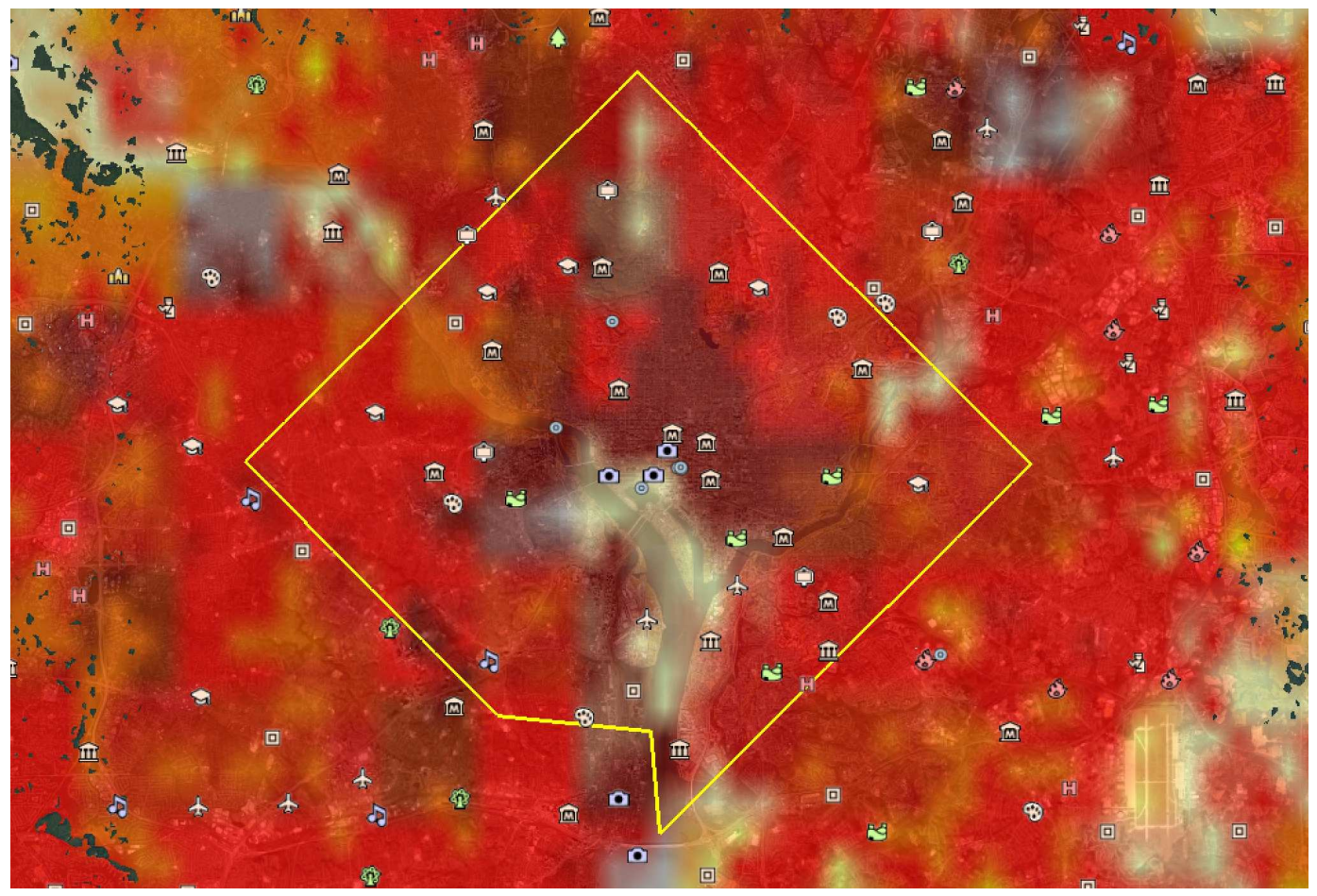

Fig. 3: Tests 0005 and 0006.

Test0017_va_exclude_12_tiles. Tests population counting with an exclusion polygon file specified via the PopLib_exclusionFile environment variable. Population data are in tile files, and the exclusion includes both polygons used in Test0009-Test0012 and Test0013-Test0016, respectively. Refer to Fig. 6 and 7 .

Test0018_va_exclude_12_tiles_ini. Duplicates Test0017 with the exclusion polygon specified in the ini file instead of the environment variable.

Test0019_va_exclude_12_rasters. Duplicates Test0017 with population data as rasters.

Test0020_va_exclude_12_rasters_ini. Duplicates Test0018 with population data as rasters.

Test0021_va_exclude_1n_tiles. Tests population counting with an exclusion polygon file specified via the PopLib_exclusionFile environment variable. Population data are in tile files, and the exclusion file specifies a population count of 50,000 inside the exclusion polygon. Both the exclusion and input polygons are identical as for Test0009.

Test0022_va_exclude_1n_tiles_ini. Duplicates Test0021 with the exclusion polygon specified in the ini file instead of the environment variable.

Test0023_va_exclude_1n_rasters. Duplicates Test0021 with population data as rasters.

Test0024_va_exclude_1n_rasters_ini. Duplicates Test0022 with population data as rasters. 


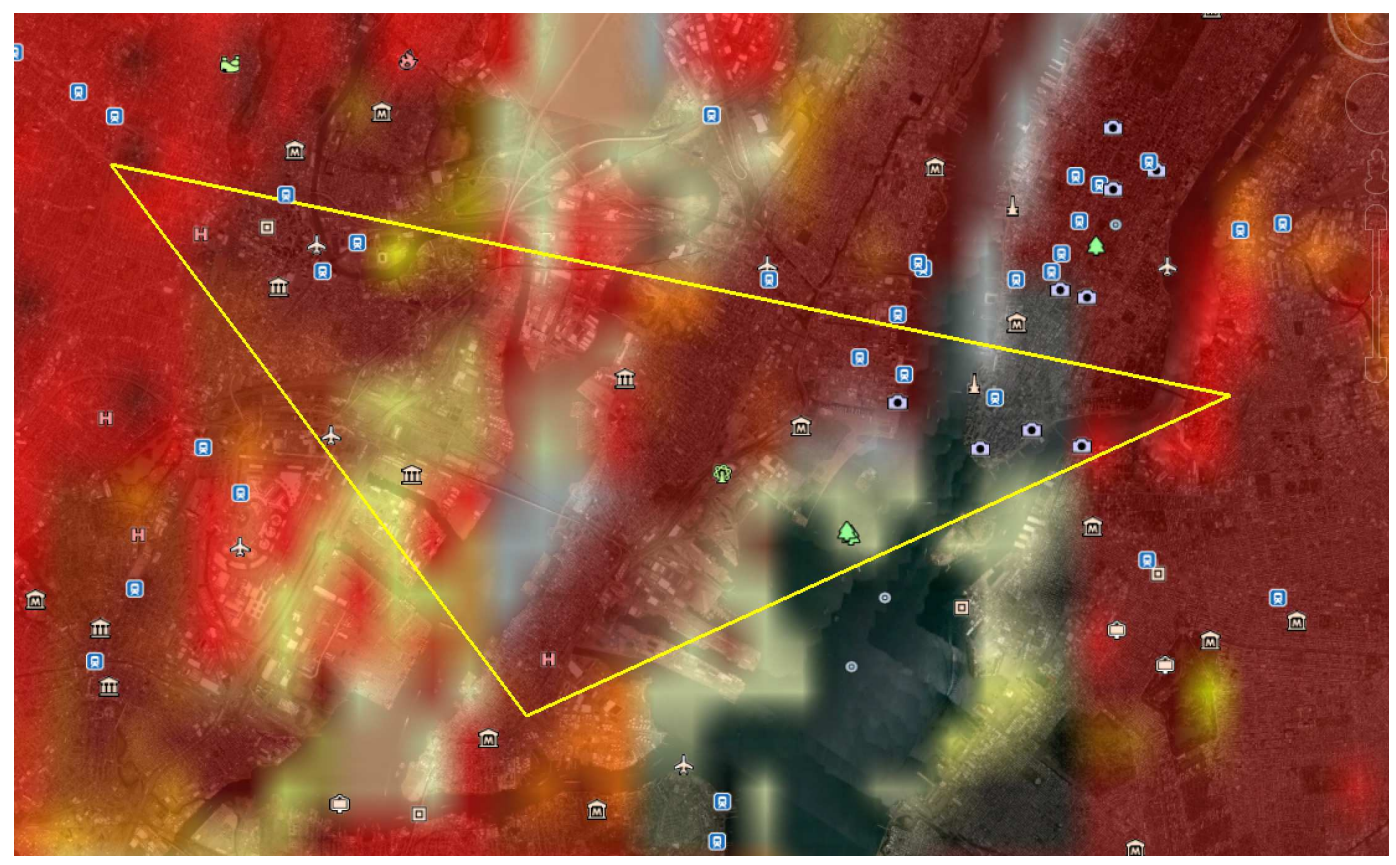

Fig. 4: Tests 0007 and 0008.

Test0025_va_exclude_2n_tiles. Tests population counting with an exclusion polygon file specified via the PopLib_exclusionFile environment variable. Population data are in tile files, and the exclusion file specifies a population count of 65,000 inside the exclusion polygon. Both the exclusion and input polygons are identical as for Test0013.

Test0026_va_exclude_2n_tiles_ini. Duplicates Test0025 with the exclusion polygon specified in the ini file instead of the environment variable.

Test0027_va_exclude_2n_rasters. Duplicates Test0025 with population data as rasters.

Test0028_va_exclude_1n_rasters_ini. Duplicates Test0026 with population data as rasters.

Test0029_va_exclude_12n_tiles. Tests population counting with two exclusion polygons in a file specified via the PopLib_exclusionFile environment variable. Population data are in tile files, and the exclusion file specifies a population count of 100,000 inside the first exclusion polygon. Both the exclusion and input polygons are identical as for Test0017.

Test0030_va_exclude_12n_tiles_ini. Duplicates Test0029 with the exclusion polygon specified in the ini file instead of the environment variable.

Test0031_va_exclude_12n_rasters. Duplicates Test0029 with population data as rasters.

Test0032_va_exclude_12n_rasters_ini. Duplicates Test0030 with population data as rasters.

Test0035_i258_exclude_tech_tiles. Tests population counting in a complex polygon with a 


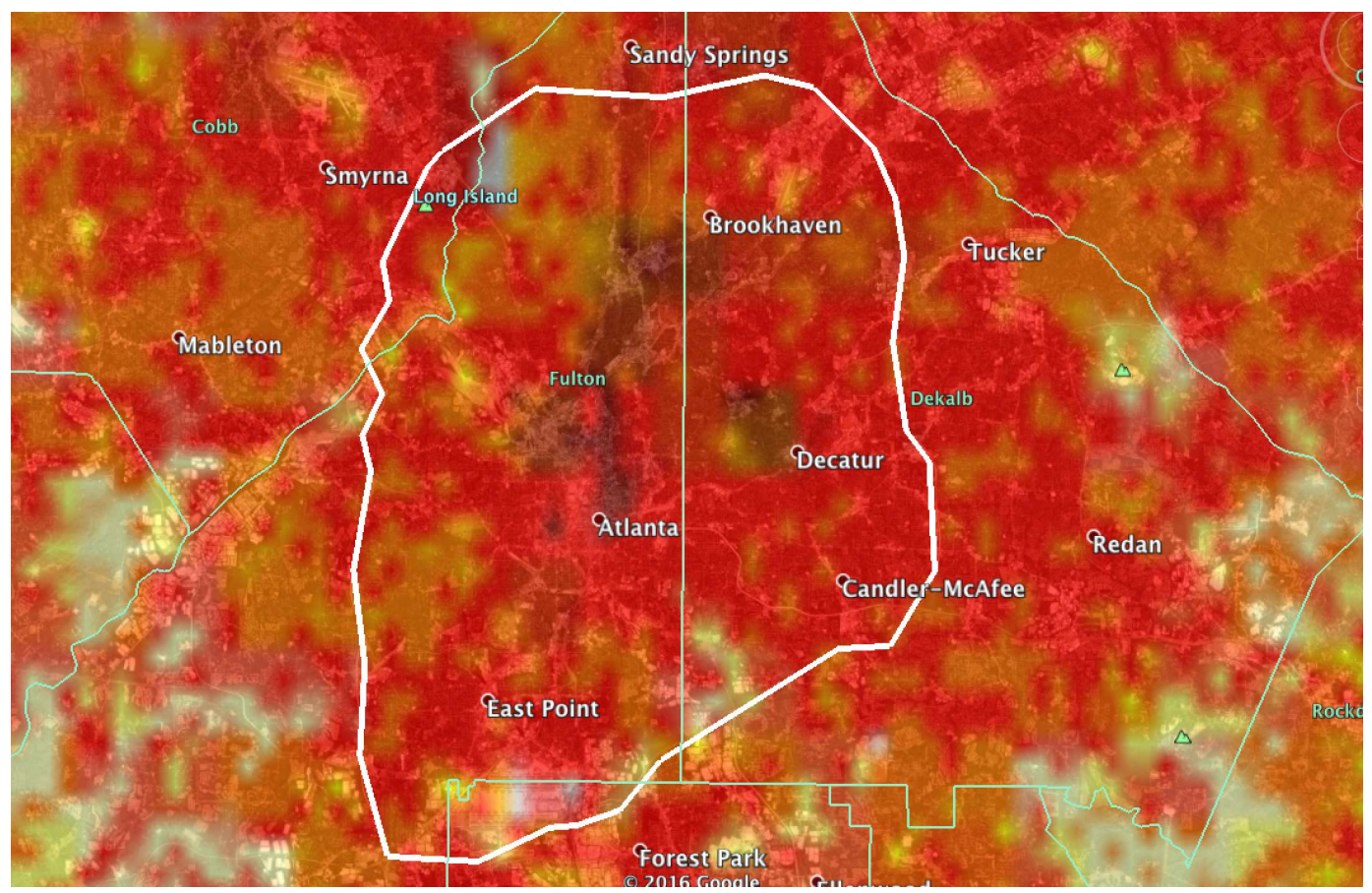

Fig. 5: Tests 0033 and 0034.

wholly contained exclusion polygon specified via the PopLib_exclusionFile environment variable. Population data are in tile files. The population data, input polygon (white), and exclusion polygon (red) are depicted in Fig. 8.

Test0036_i258_exclude_tech_tiles_ini. Duplicates Test0035 with the exclusion polygon specified in the ini file instead of the environment variable.

Test0037_i258_exclude_tech_rasters. Duplicates Test0035 with population data as rasters.

Test0038_i258_exclude_tech_rasters_ini. Duplicates Test0036 with population data as rasters.

Test0039_i258_exclude_tech_fixed_tiles. Tests population counting in a complex polygon with a wholly contained exclusion polygon specified via the PopLib_exclusionFile environment variable. Population data are in tile files, and the exclusion file specifies a population of 1000 inside the exclusion polygon. The population data, input polygon, and exclusion polygon are the same as for Test0035.

Test0040_i258_exclude_tech_fixed_tiles_ini. Duplicates Test0039 with the exclusion polygon specified in the ini file instead of the environment variable.

Test0041_i258_exclude_tech_fixed_rasters. Duplicates Test0039 with population data as rasters.

Test0042_i258_exclude_tech_fixed_rasters_ini. Duplicates Test0040 population data as rasters. 


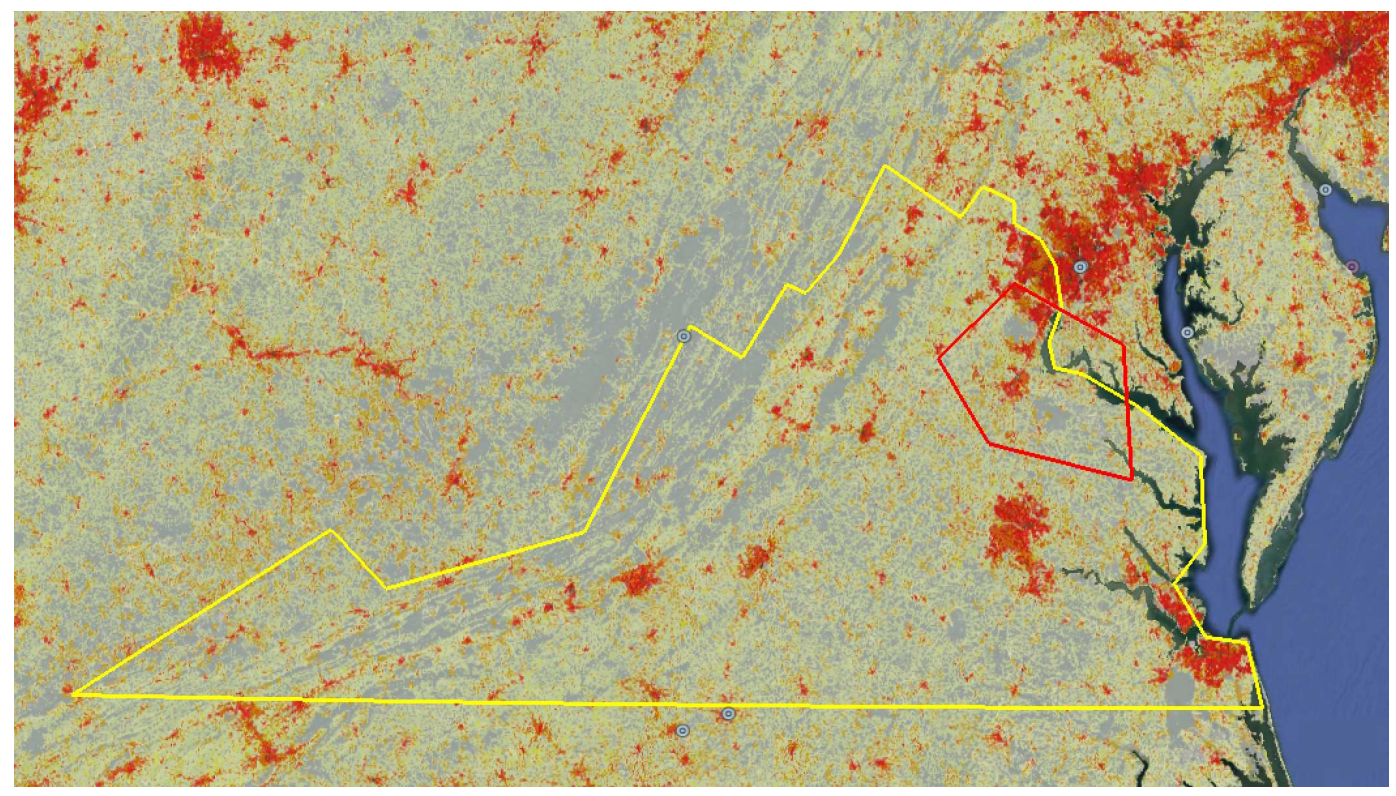

Fig. 6: Tests 0009-0012.

\subsection{MGRS COORDINATES}

Test0043_mgrs. Tests correct conversion between MGRS and geodetic coordinates.

Test0044_va_exclude_12_mgrs_12_tiles. This test is identical to Test0017 except the exclusion polygons are specified in MGRS coordinates. Population data are in tile files, and the exclusion file is specified via the PopLib_exclusionFile environment variable.

Test0045_va_exclude_12_mgrs_12_tiles_ini. Duplicates Test0044 with the exclusion polygon specified in the ini file instead of the environment variable.

Test0046_va_exclude_12_mgrs_12_rasters. Duplicates Test0044 with population data as rasters.

Test0047_va_exclude_12_mgrs_12_rasters_ini. Duplicates Test0045 with population data as rasters.

Test0048_va_exclude_12_mgrs_1_tiles. This test is identical to Test0044 except the first polygon in the exclusion file is specified in MGRS coordinates and the second polygon in geodetic coordinates. Population data are in tile files, and the exclusion file is specified via the PopLib_exclusionFile environment variable.

Test0049_va_exclude_12_mgrs_1_rasters. Duplicates Test0048 with population data as rasters.

Test0050_va_exclude_12_mgrs_2_tiles. This test is identical to Test0044 except the first polygon in the exclusion file is specified in geodetic coordinates and the second polygon in MGRS.

Population data are in tile files, and the exclusion file is specified via the PopLib_exclusionFile 


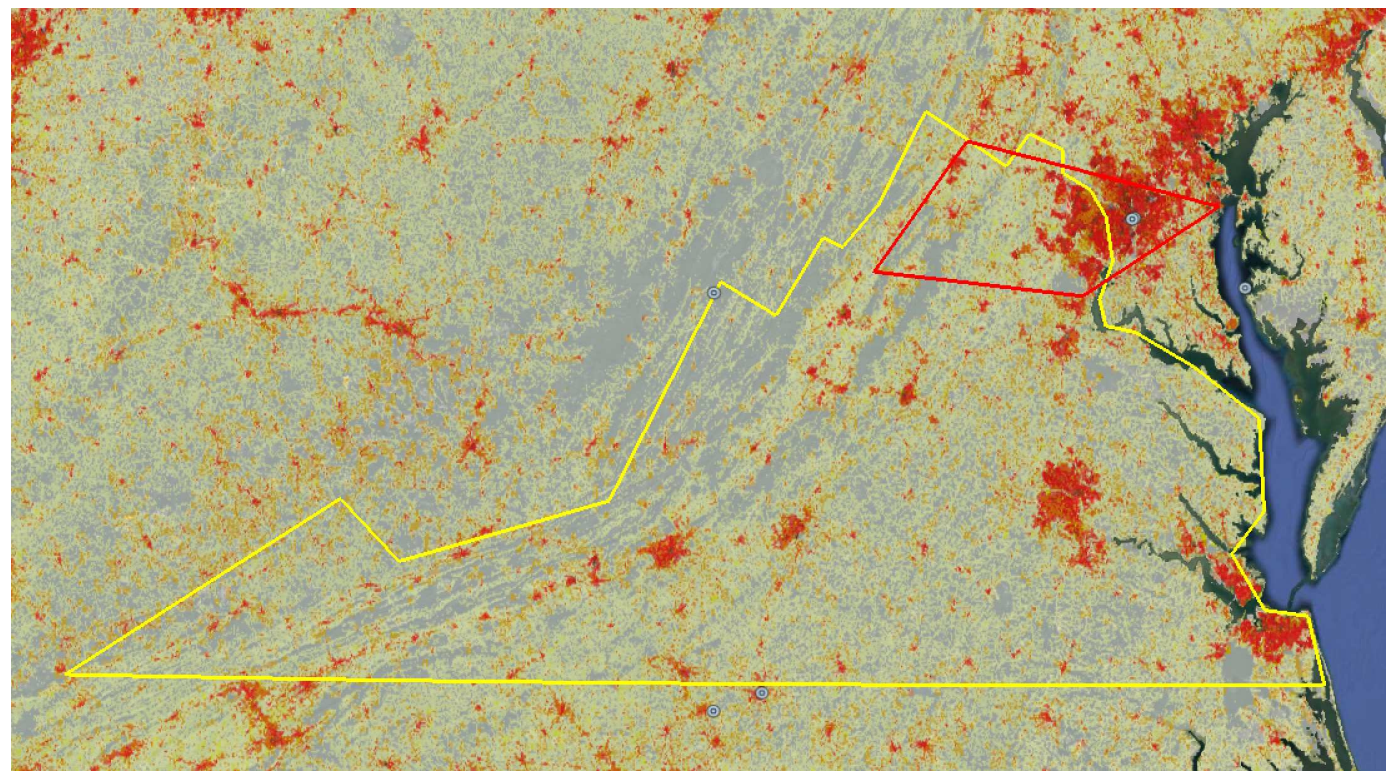

Fig. 7: Tests 0013-0016.

environment variable.

Test0051_va_exclude_12_mgrs_2_rasters. Duplicates Test0050 with population data as rasters.

\subsection{HIGH RESOLUTION RASTER DATA}

Test0052_mosul_raster_only_inner. Tests population counting with special high resolution raster data and the input polygon wholly contained within the raster. The population data and input polygon are depicted in Fig. 9 .

Test0053_mosul_raster_only_cut. Tests population counting with special high resolution raster data, where the input polygon extends outside the raster but transects it. The population data and input polygon are depicted in Fig. 10.

Test0054_mosul_raster_only_outer. Tests population counting with special high resolution raster data, where raster is wholly contained within the input polygon. The population data and input polygon are depicted in Fig. 11.

Test0055_mosul_raster_levant_raster_inner. Tests population counting with special high resolution raster data, a background raster with lower resolution, and an input polygon wholly contained within the high resolution raster. The population data and input polygon are depicted in Fig. 12 .

Test0056_mosul_raster_levant_raster_cut. Tests population counting with special high resolution raster data, a background raster with lower resolution, and an input polygon that 


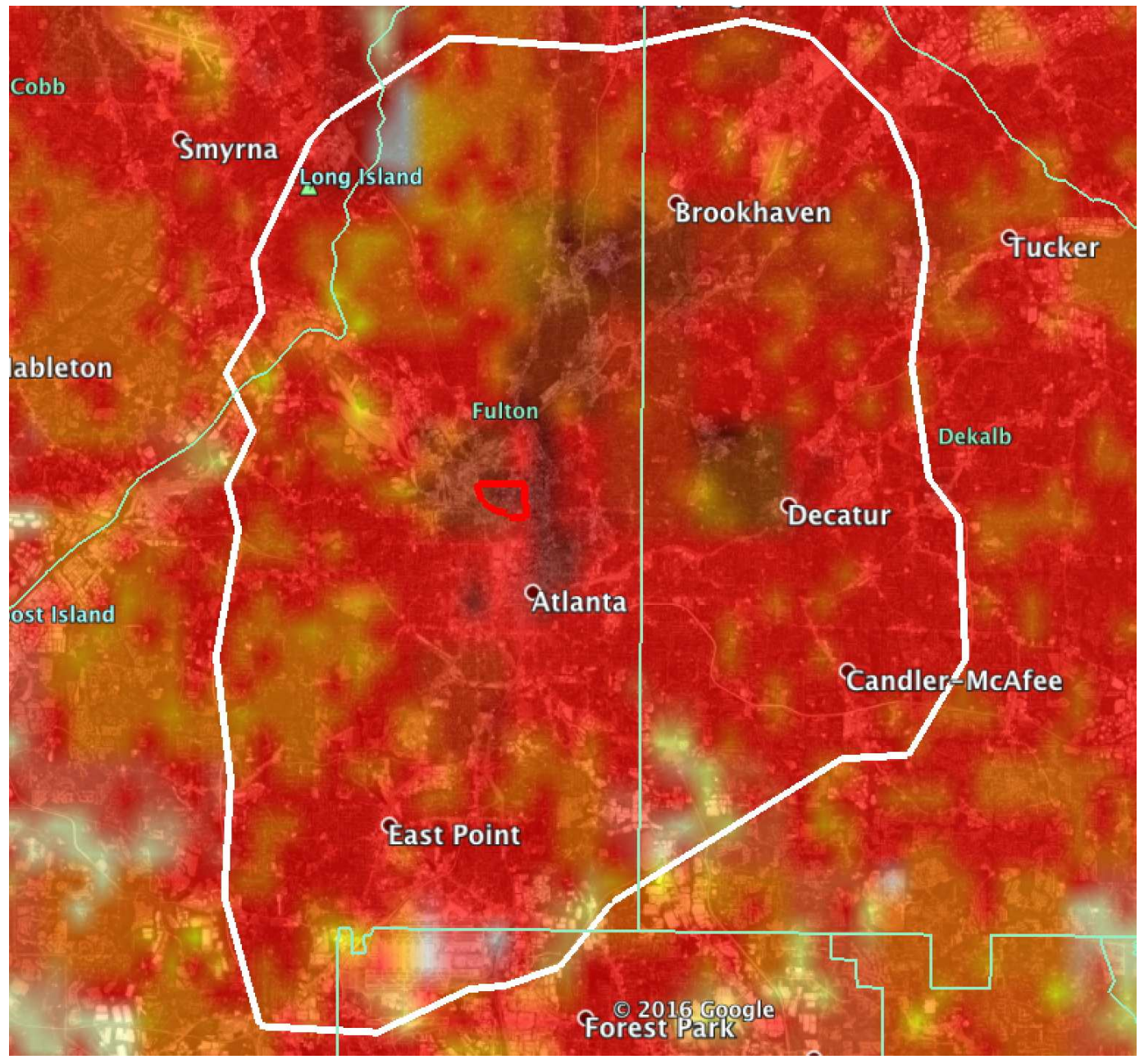

Fig. 8: Tests 0035-0038.

extends outside the high resolution raster but transects it. The population data and input polygon are depicted in Fig. 13.

Test0057_mosul_raster_levant_raster_outer. Tests population counting with special high resolution raster data, a background raster with lower resolution, and an input polygon that wholly contains the high resolution raster. The population data and input polygon are depicted in Fig. 14

\subsection{RASTERS AND TILES TOGETHER}

Test0058_mosul_raster_levant_tile_inner. This test is identical to Test0055 except the background population data are in tiles.

Test0059_mosul_raster_levant_tile_cut. This test is identical to Test0056 except the background 


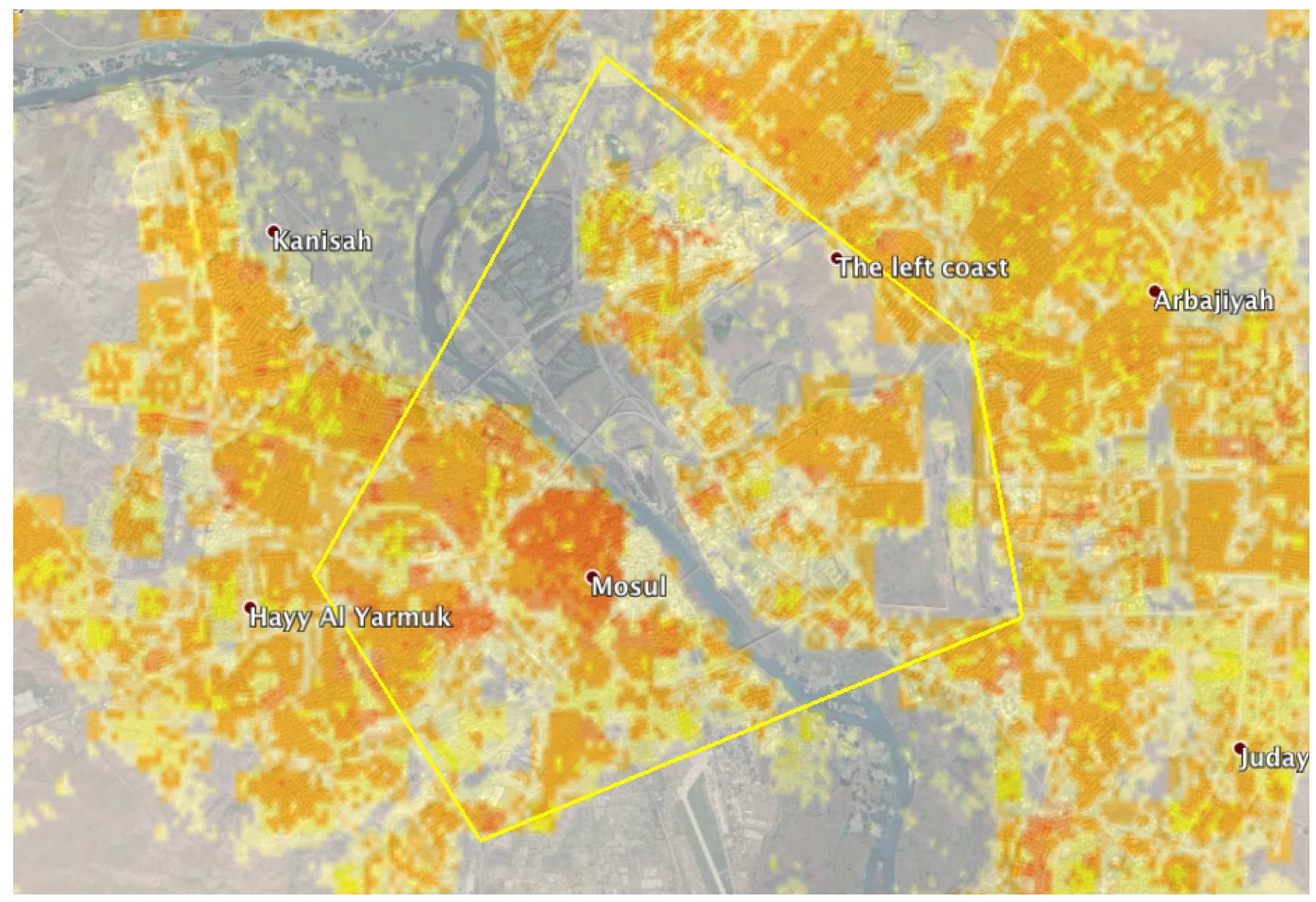

Fig. 9: Test 0052.

population data are in tiles.

Test0060_mosul_raster_levant_tile_outer. This test is identical to Test0057 except the background population data are in tiles.

Test0061_mosul_rasters_only. For comparison purposes, this test counts population in a directory containing raster files only. The population data and input polygon are identical to Test0057.

Test0062_mosul_rasters_and_tiles. Tests with the same input data and polygon as Test0061, but the background data are in tiles in the same directory as the high resolution raster. 


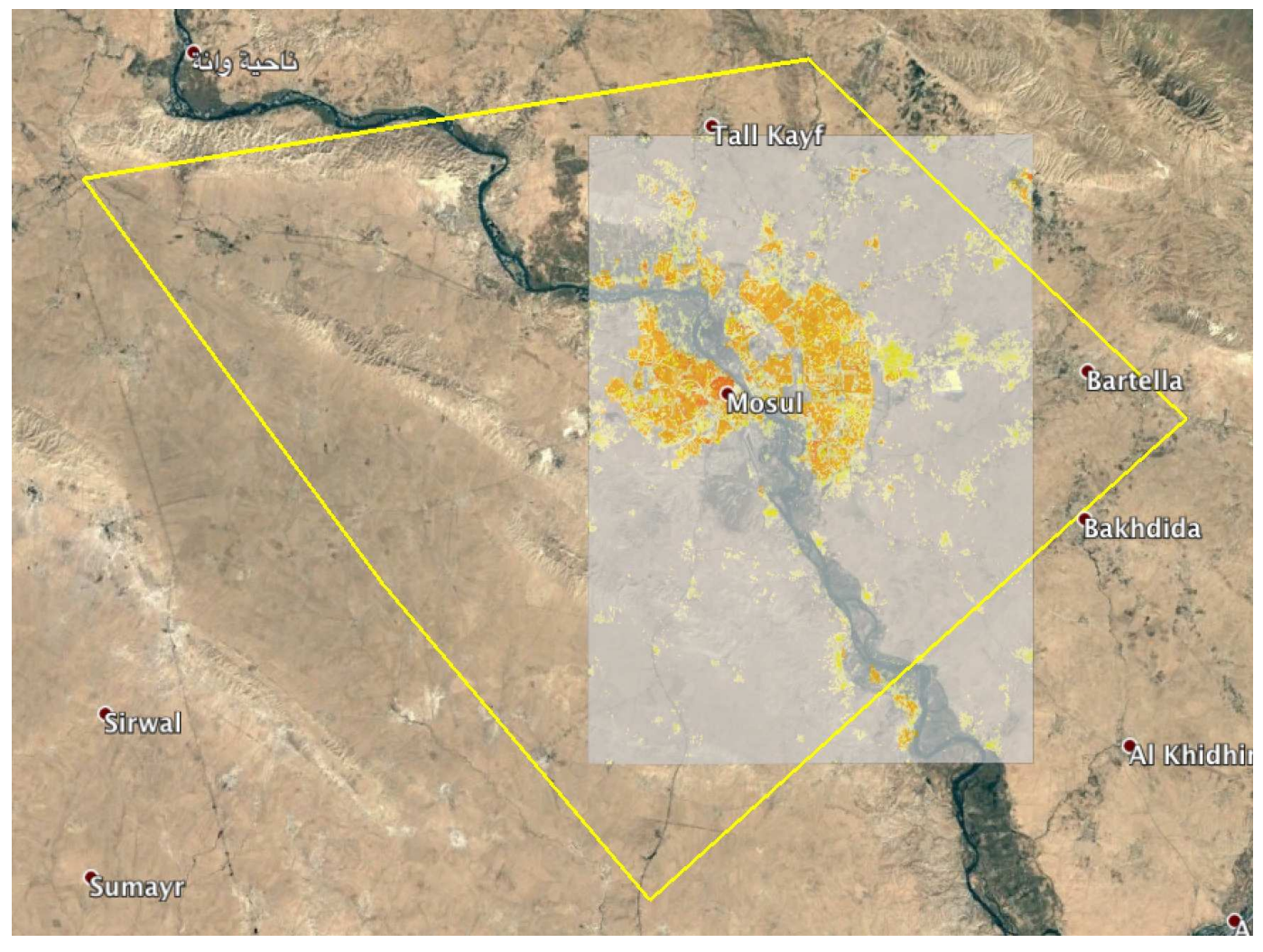

Fig. 10: Test 0053. 


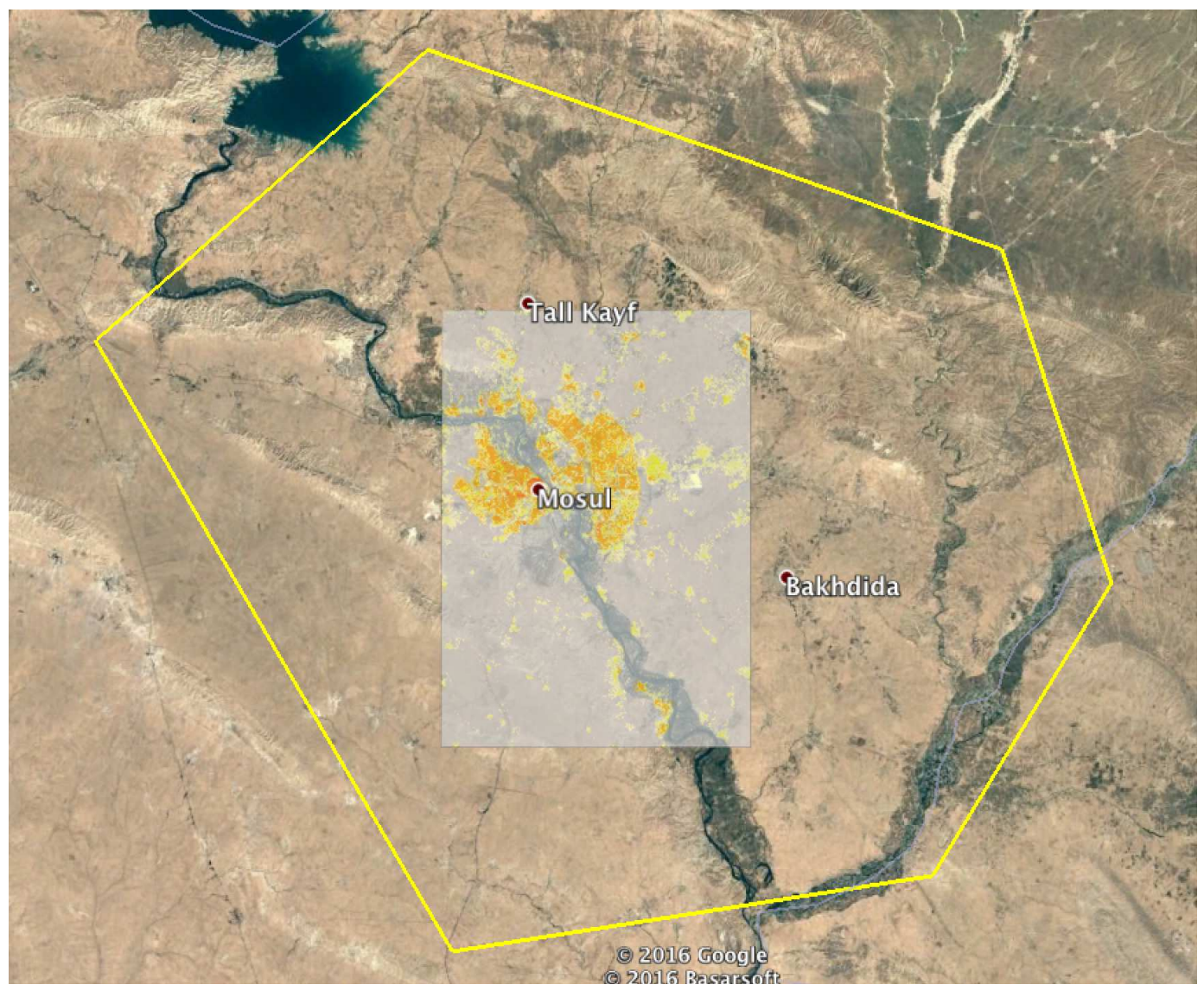

Fig. 11: Test 0054. 


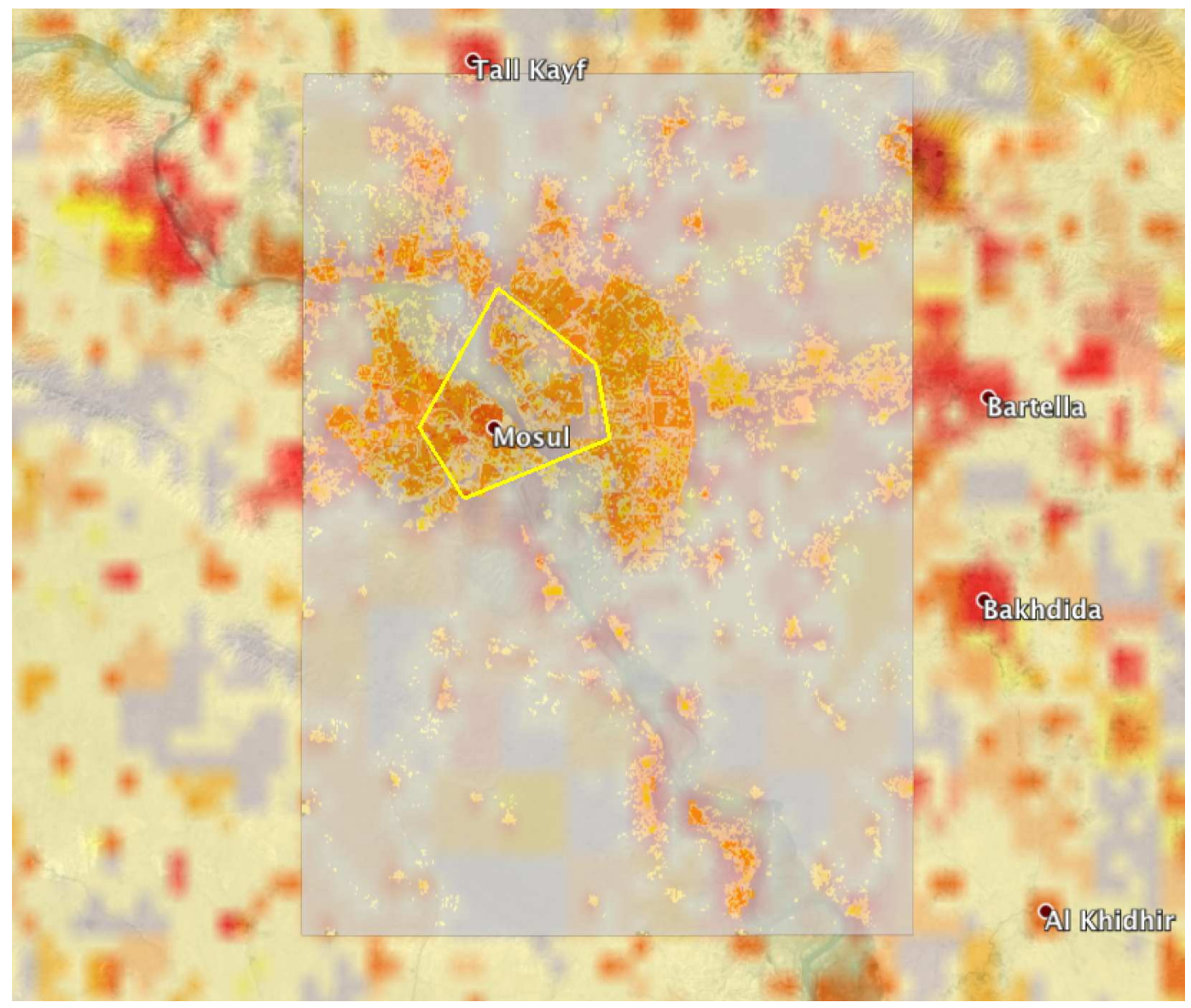

Fig. 12: Test 0055. 


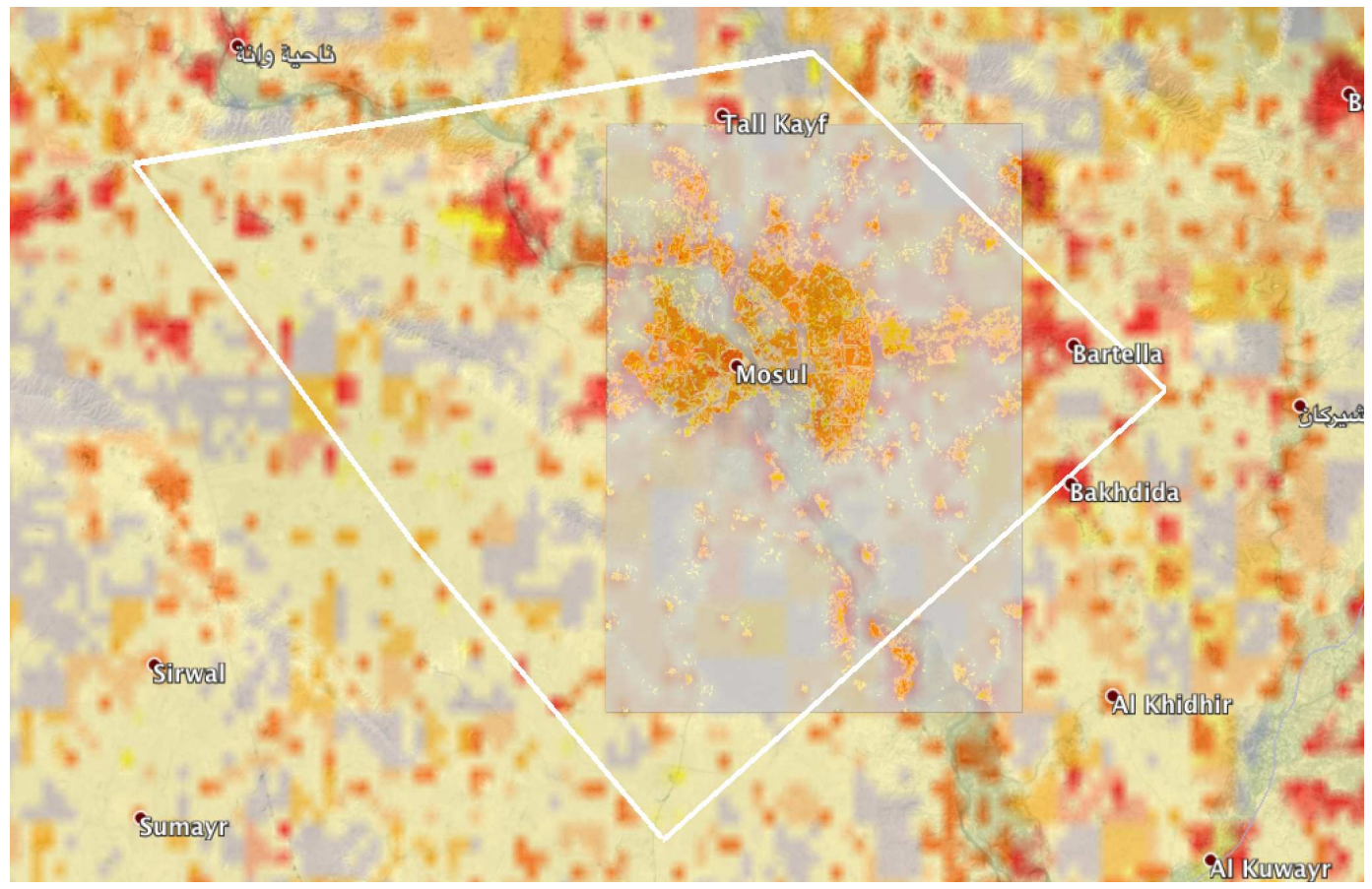

Fig. 13: Test 0056.

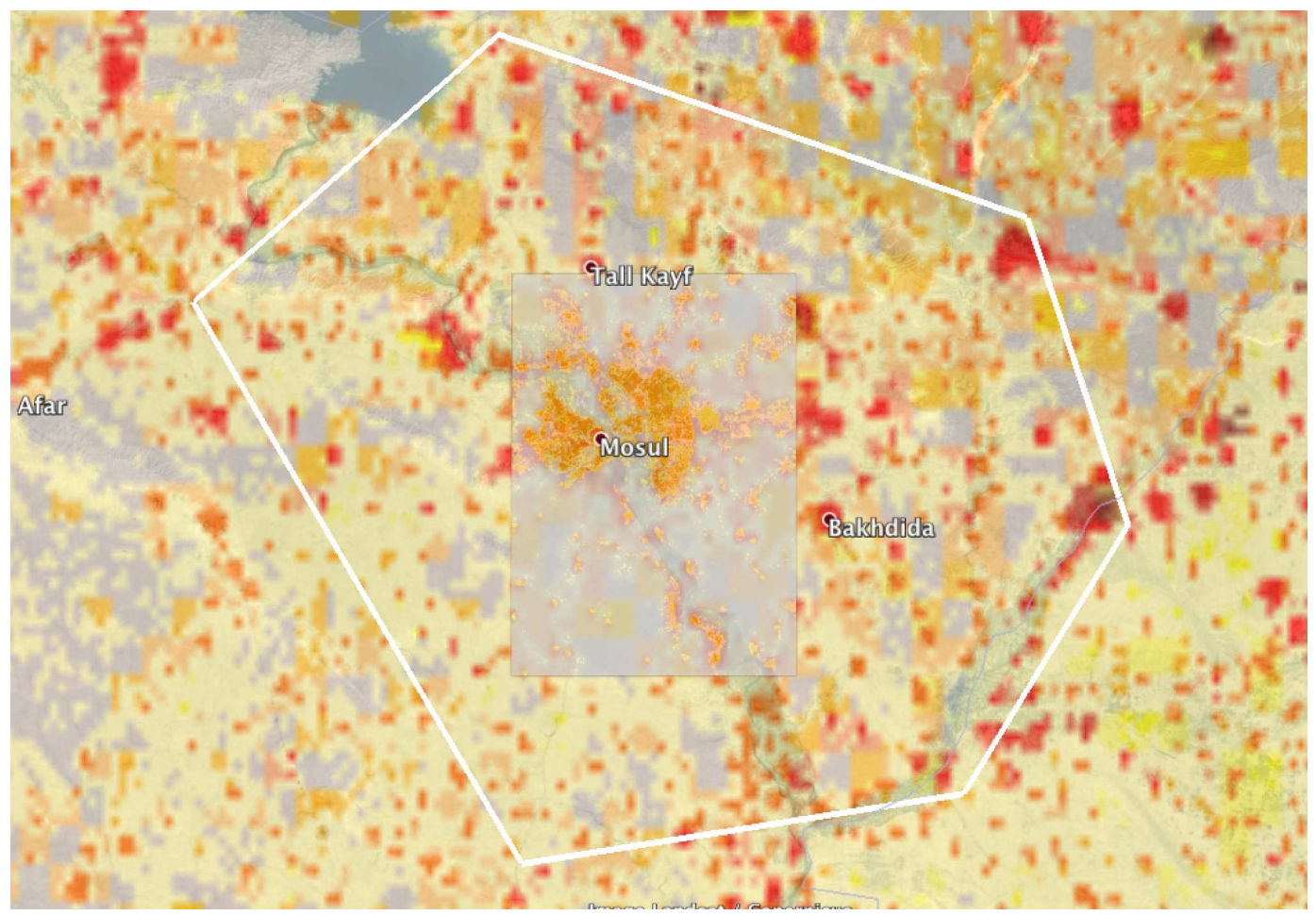

Fig. 14: Test 0057. 


\section{TEST RESULTS}

\section{CTest consolidates all test results into a single report, listed below.}

Test project C:/Users/re7/src/Release

Start 1: test0001_dc_around_tiles

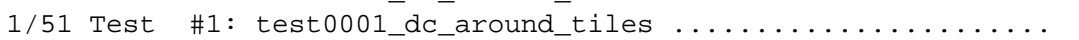

Start 2: test0002_dc_around_rasters

2/51 Test \#2: test0002_dc_around_rasters $\ldots \ldots \ldots \ldots \ldots \ldots \ldots$

Start 3: test0003_dc_inner_tiles

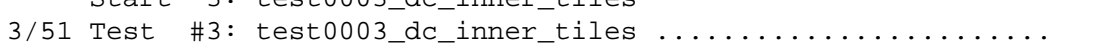
Start 4: test0004_dc_inner_rasters

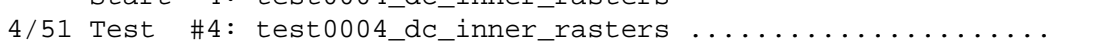
Start 5: test0005_dc_diamond_tiles

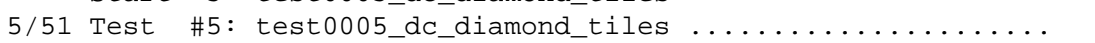
Start 6: test0006_dc_diamond_rasters

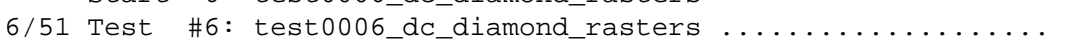
Start 7: test0007_ny_triangle_tiles

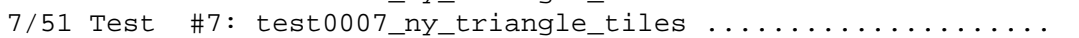
Start 8: test0008_ny_triangle_rasters

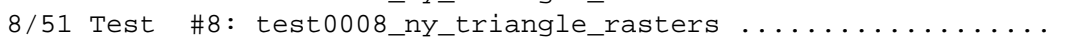
Start 9: test0009_va_exclude_1_tiles

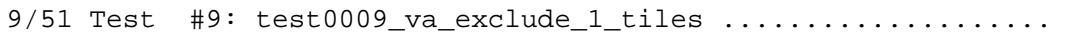
Start 10: test0010_va_exclude_1_tiles_ini

10/51 Test \#10: test0010_va_exclude_1_tiles_ini ............. Start 11: test0011_va_exclude_1_rasters

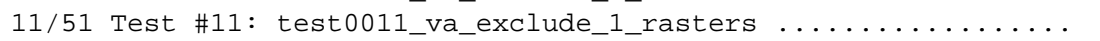
Start 12: test0012_va_exclude_1_rasters_ini

12/51 Test \#12: test0012_va_exclude_1_rasters_ini ........... Start 13: test0013_va_exclude_2_tiles

13/51 Test \#13: test0013_va_exclude_2_tiles ................ Start 14: test0014_va_exclude_2_tiles_ini

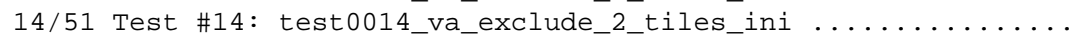
Start 15: test0015_va_exclude_2_rasters

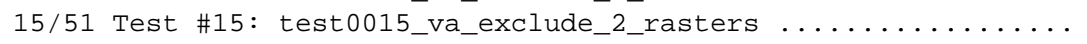
Start 16: test0016_va_exclude_2_rasters_ini

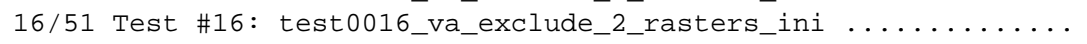
Start 17: test0017_va_exclude_12_tiles

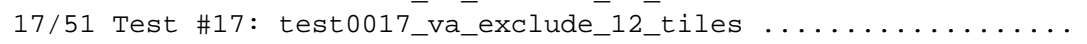
Start 18: test0018_va_exclude_12_tiles_ini

18/51 Test \#18: test0018_va_exclude_12_tiles_ini ............ Start 19: test0019_va_exclude_12_rasters

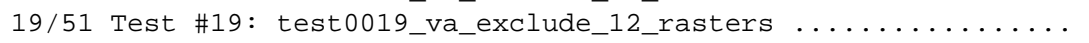
Start 20: test0020_va_exclude_12_rasters_ini

20/51 Test \#20: test0020_va_exclude_12_rasters_ini ............ Start 21: test0021_va_exclude_1n_tiles

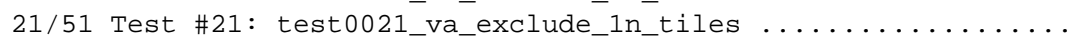
Start 22: test0022_va_exclude_1n_tiles_ini

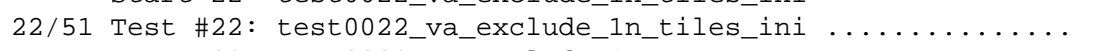
Start 23: test0023_va_exclude_1n_rasters

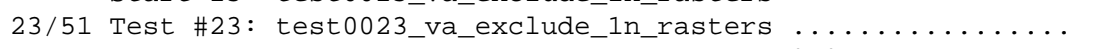
Start 24: test0024_va_exclude_1n_rasters_ini

24/51 Test \#24: test0024_va_exclude_1n_rasters_ini ........... Start 25: test0025_va_exclude_2n_tiles

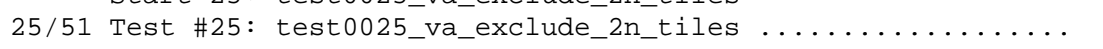
Start 26: test0026_va_exclude_2n_tiles_ini

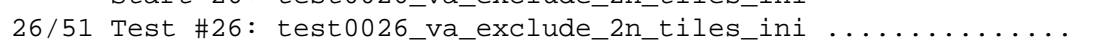
Start 27: test0027_va_exclude_2n_rasters

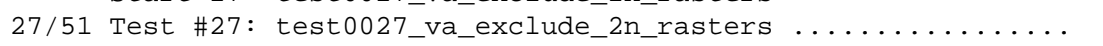
Start 28: test0028_va_exclude_2n_rasters_ini

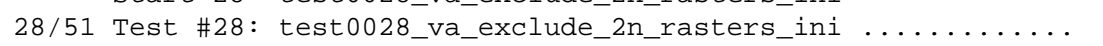
Start 29: test0029_va_exclude_12n_tiles

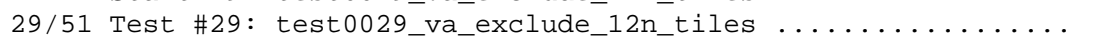
Start 30: test0030_va_exclude_12n_tiles_ini

\begin{tabular}{|c|c|c|}
\hline Passed & 0.19 & sec \\
\hline Passed & 0.20 & sec \\
\hline Passed & 0.17 & $\mathrm{sec}$ \\
\hline Passed & 0.16 & sec \\
\hline Passed & 0.17 & $\mathrm{sec}$ \\
\hline Passed & 0.17 & sec \\
\hline Passed & 0.17 & sec \\
\hline Passed & 0.17 & $\mathrm{sec}$ \\
\hline Passed & 0.23 & $\mathrm{sec}$ \\
\hline Passed & 0.23 & $\mathrm{sec}$ \\
\hline Passed & 0.30 & $\mathrm{sec}$ \\
\hline Passed & 0.30 & sec \\
\hline Passed & 0.27 & $\mathrm{sec}$ \\
\hline Passed & 0.22 & sec \\
\hline Passed & 0.28 & sec \\
\hline Passed & 0.27 & sec \\
\hline Passed & 0.23 & $\mathrm{sec}$ \\
\hline Passed & 0.23 & $\mathrm{sec}$ \\
\hline Passed & 0.30 & $\mathrm{sec}$ \\
\hline Passed & 0.28 & $\mathrm{sec}$ \\
\hline Passed & 0.23 & $\mathrm{sec}$ \\
\hline Passed & 0.23 & $\mathrm{sec}$ \\
\hline Passed & 0.30 & $\mathrm{sec}$ \\
\hline Passed & 0.30 & $\mathrm{sec}$ \\
\hline Passed & 0.23 & $\mathrm{sec}$ \\
\hline Passed & 0.22 & $\mathrm{sec}$ \\
\hline Passed & 0.27 & $\mathrm{sec}$ \\
\hline Passed & 0.28 & \\
\hline ssed & 0.22 & \\
\hline
\end{tabular}

Passed $\quad 0.22 \mathrm{sec}$ 


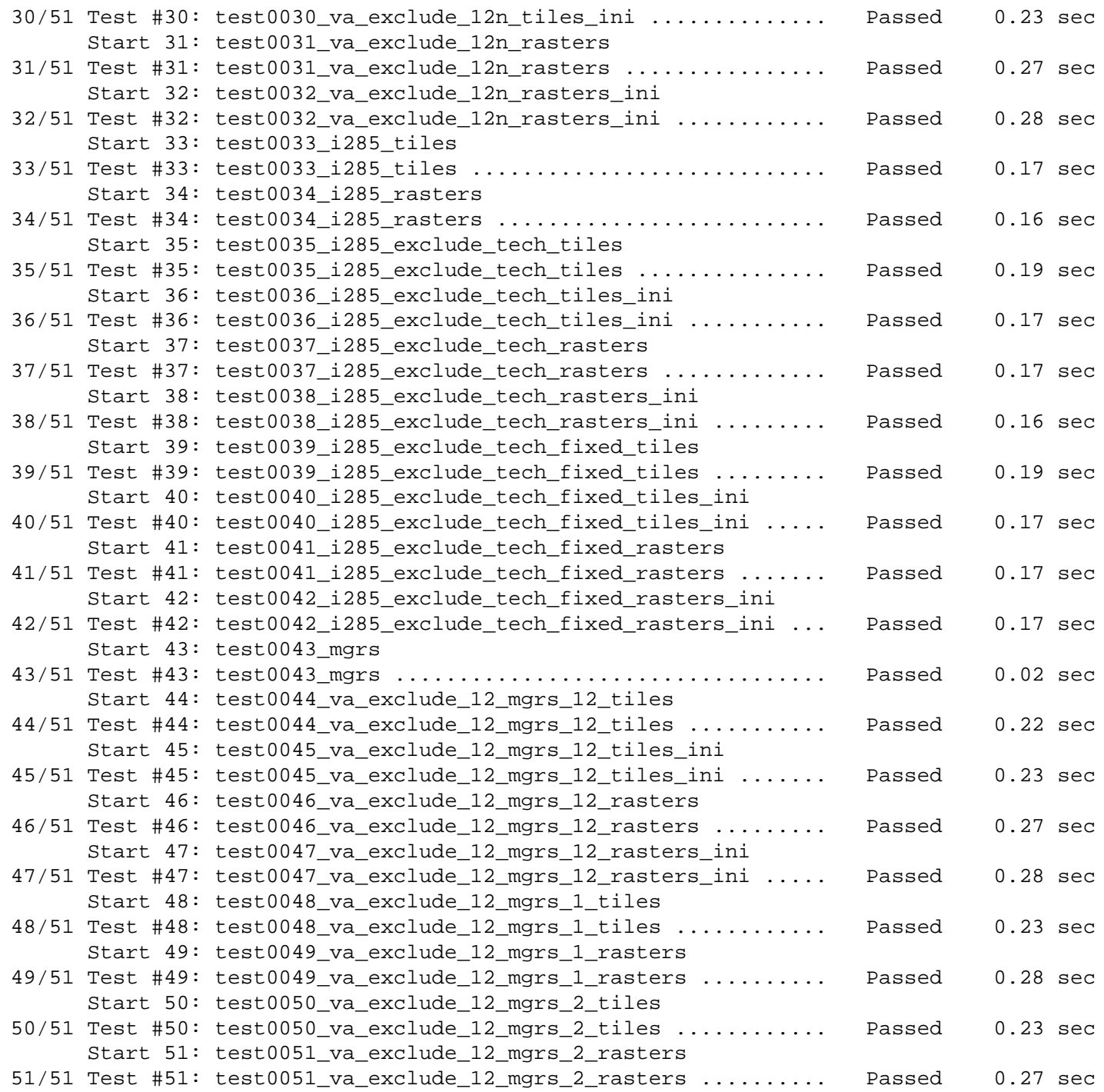

$100 \%$ tests passed, 0 tests failed out of 51

$\begin{array}{llll}\text { Label Time Summary: } & & \\ \text { exclusion } & = & 9.61 \mathrm{sec} & (40 \text { tests }) \\ \text { mgrs } & = & 0.02 \mathrm{sec}(1 \text { test }) \\ \text { rasters } & = & 6.03 \mathrm{sec}(25 \text { tests }) \\ \text { simple } & =1.73 \mathrm{sec}(10 \text { tests }) \\ \text { tiles } & = & 5.31 \mathrm{sec}(25 \text { tests })\end{array}$

Total Test time (real) $=11.44 \mathrm{sec}$ 


\section{References}

1. Kitware. CMake. https://cmake.org. 


\section{A POPLIB TEST DRIVER}

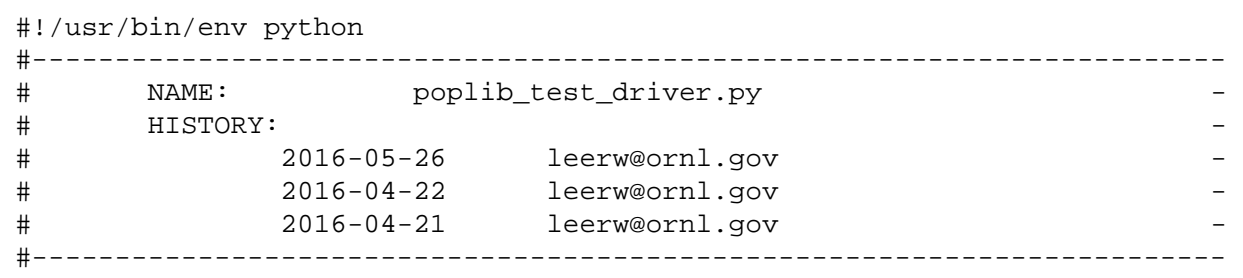

import argparse, os, subprocess, sys, tempfile, traceback

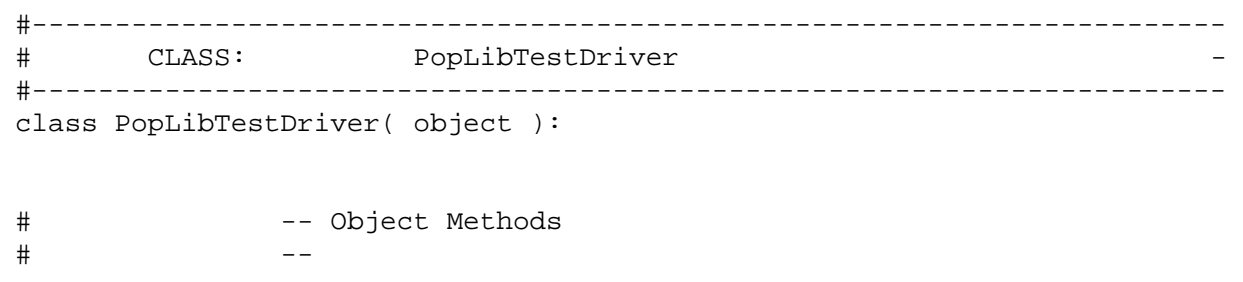

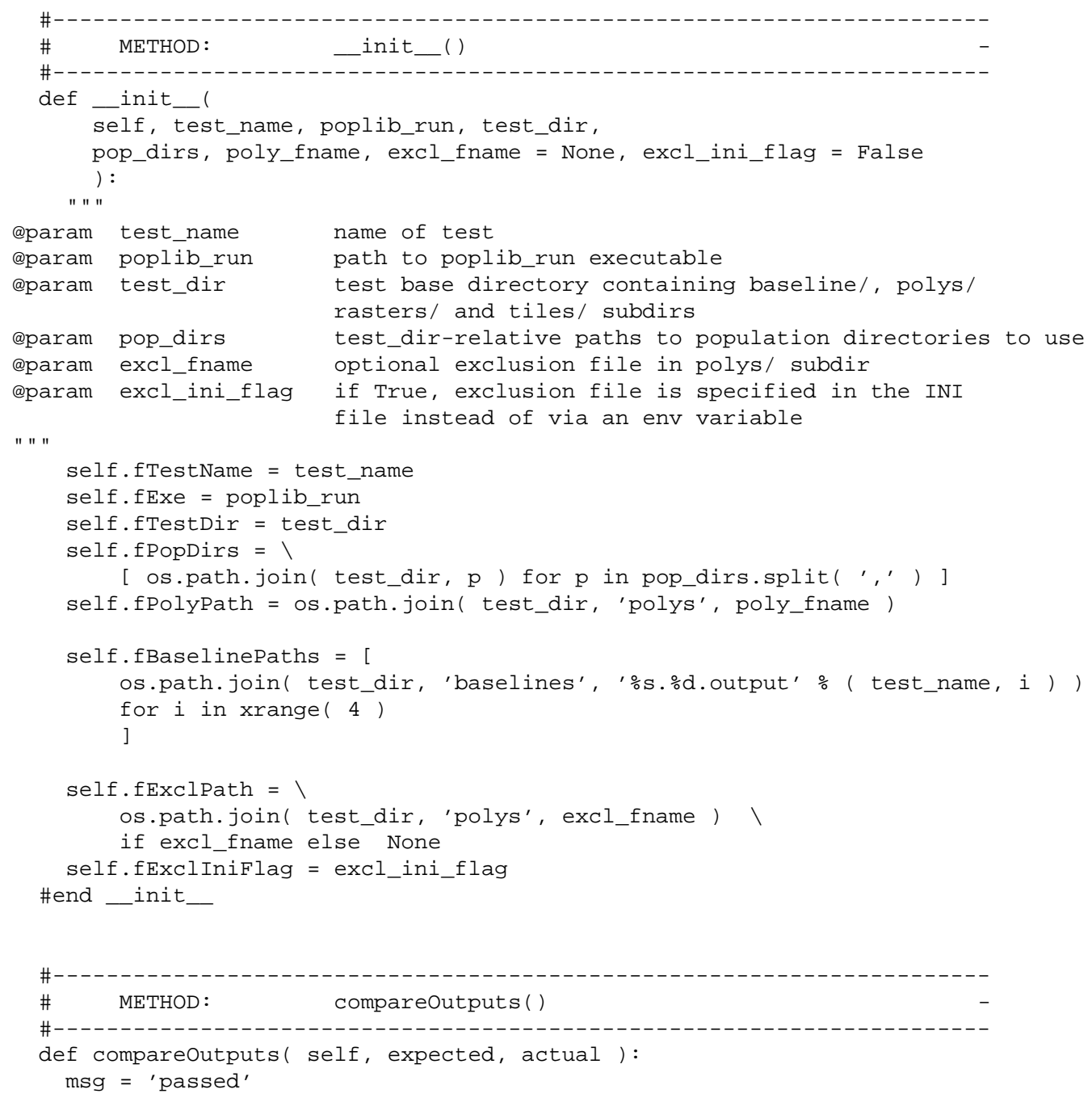




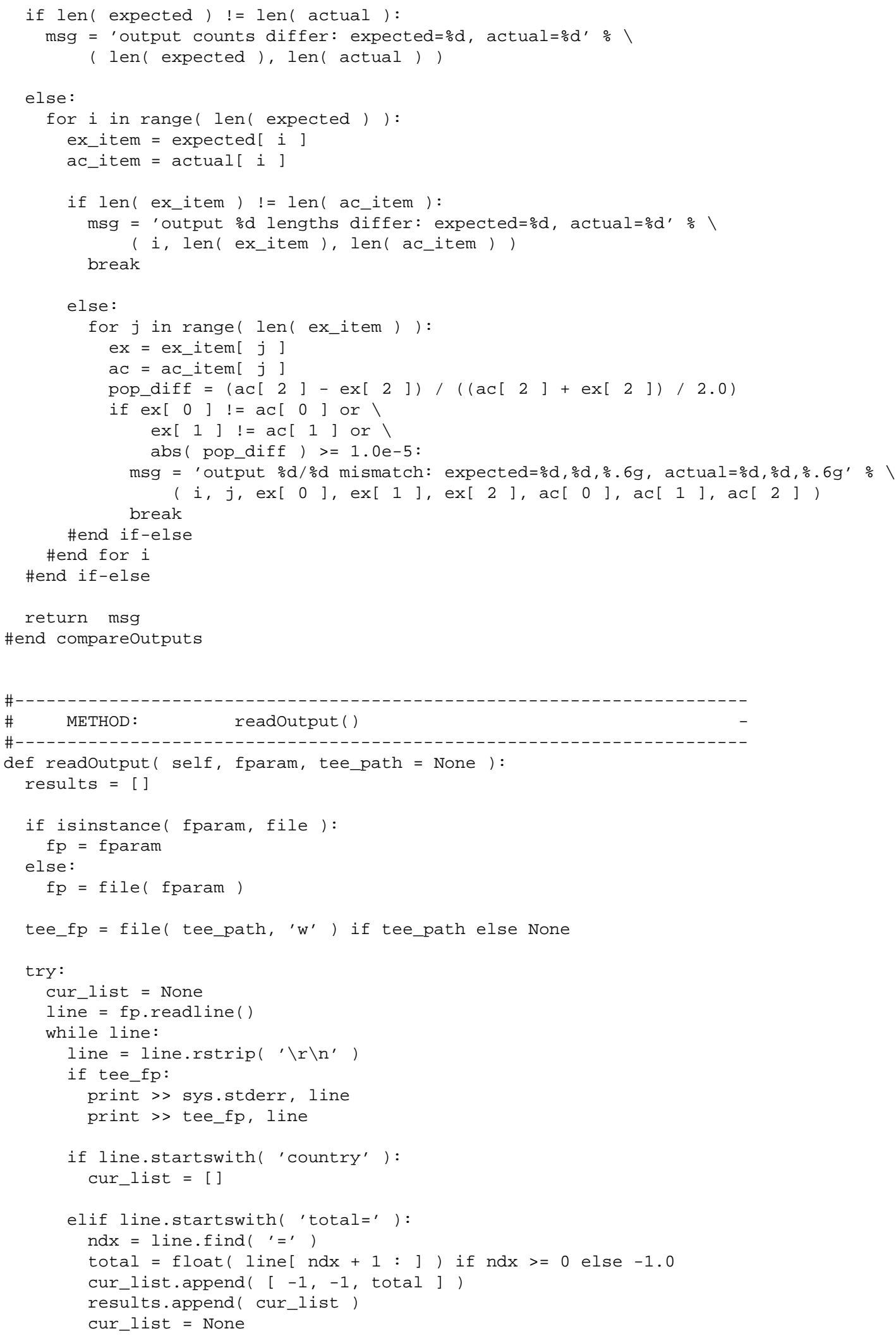




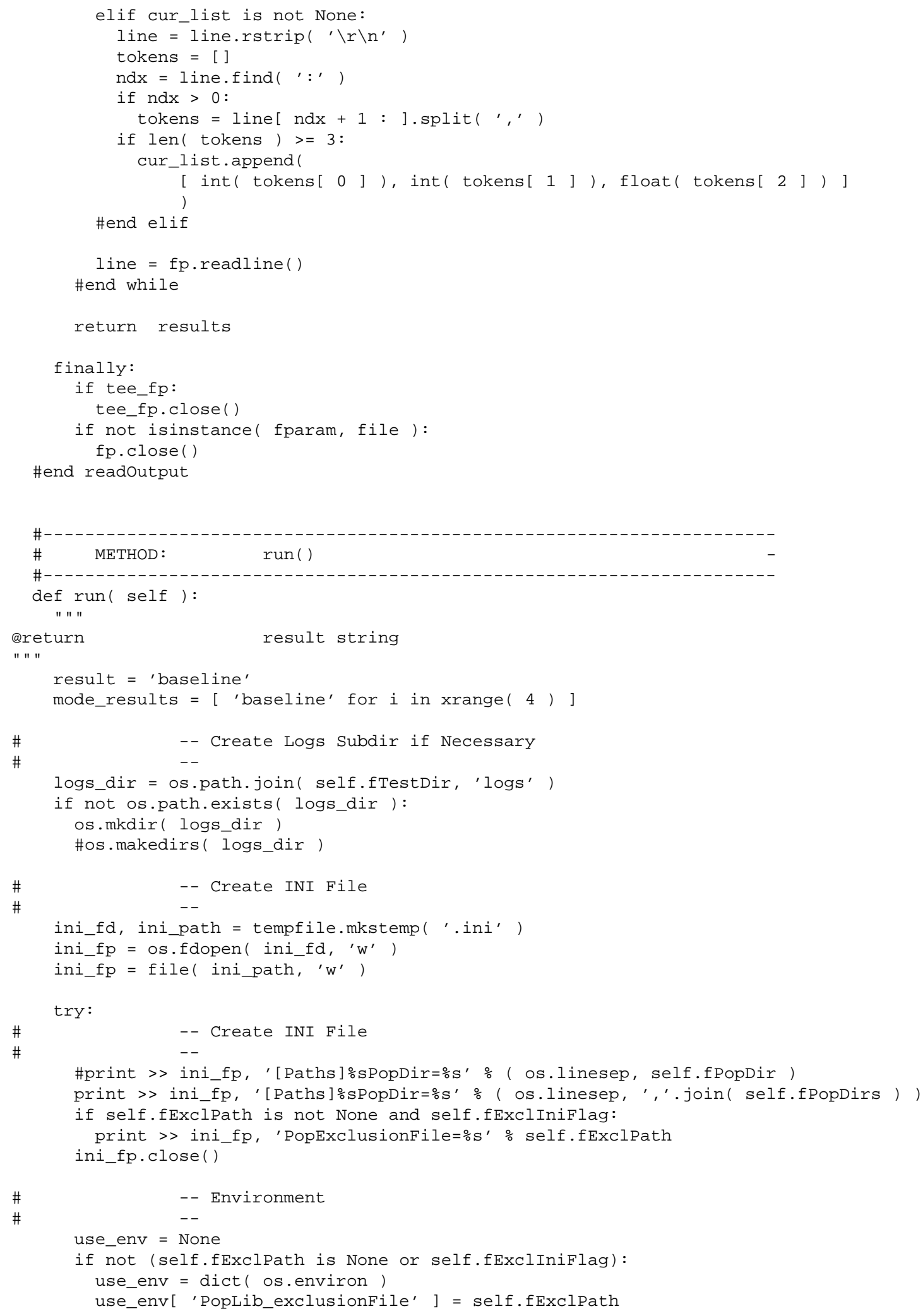




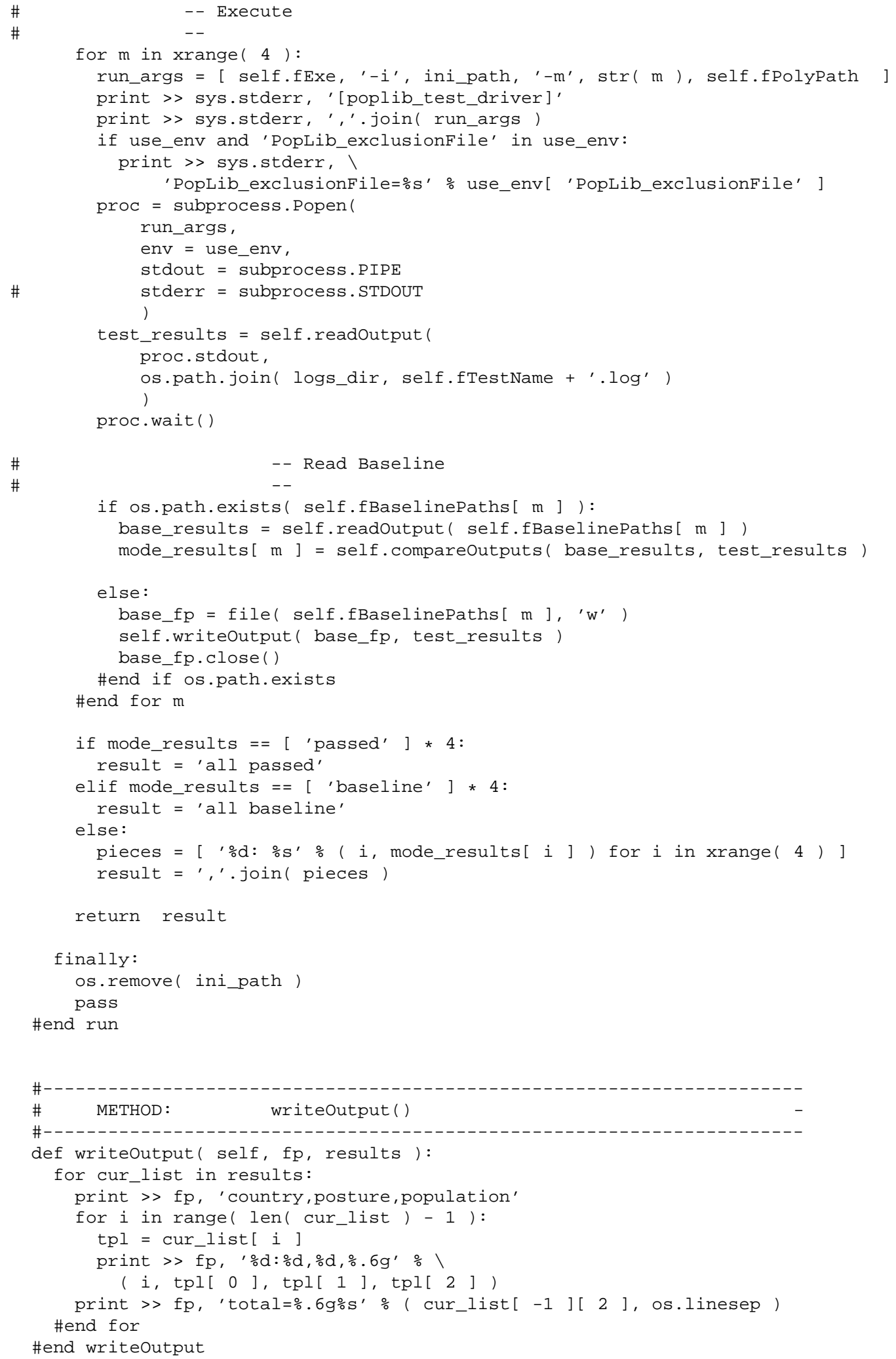




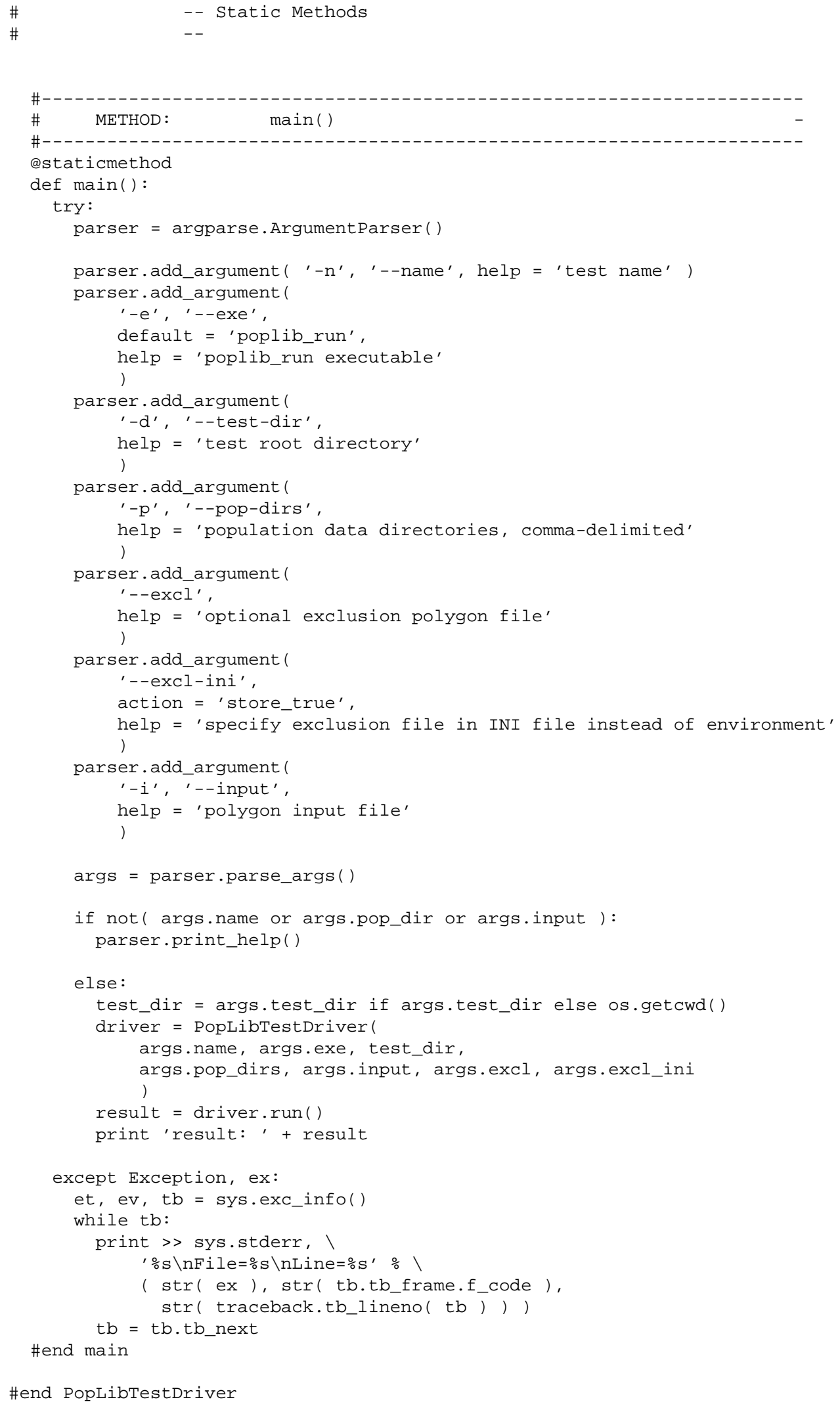


if $\underset{\text { PoplibTestDriver.main () }}{ }=$ 


\section{B CMAKE LIST FILE}

\begin{tabular}{|c|c|c|c|}
\hline \# & NAME : & oplib-tests: : CMakeLists.txt & - \\
\hline$\#$ & HISTORY: & & - \\
\hline \# & $2016-06-13$ & leerw@ornl.gov & - \\
\hline \# & Added mgrs_test. & & \\
\hline$\#$ & $2016-04-25$ & leerweornl.gov & - \\
\hline \# & $2016-04-22$ & leerw@ornl.gov & - \\
\hline
\end{tabular}

cmake_minimum_required( VERSION 2.8)

\#project ( hpac5-poplib-tests )

$\# \quad--$ Find python
$\# \quad--$
if ( NOT DEFINED PYTHON_EXECUTABLE )
find_program( PYTHON_EXECUTABLE NAMES python )

endif ()

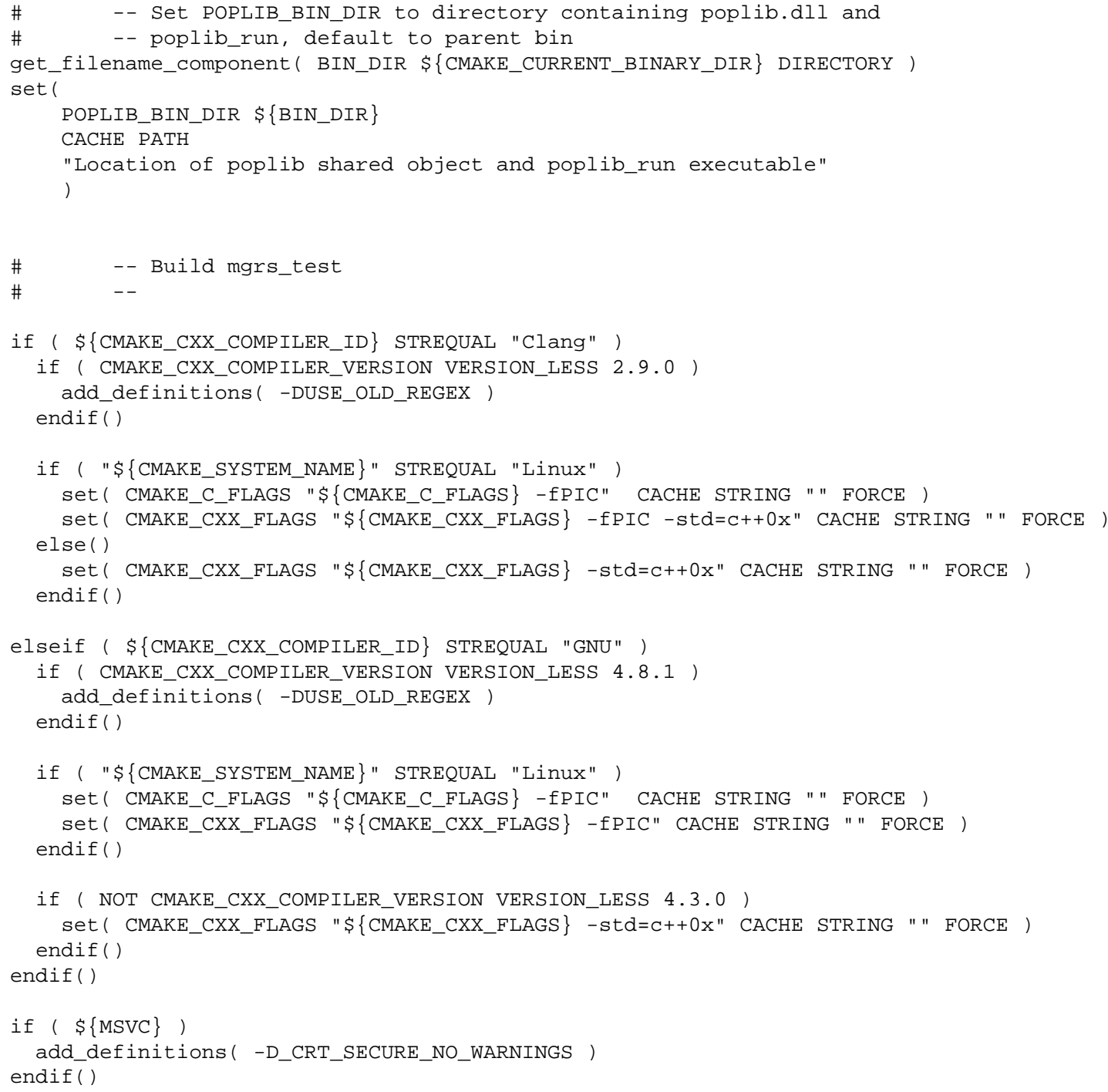




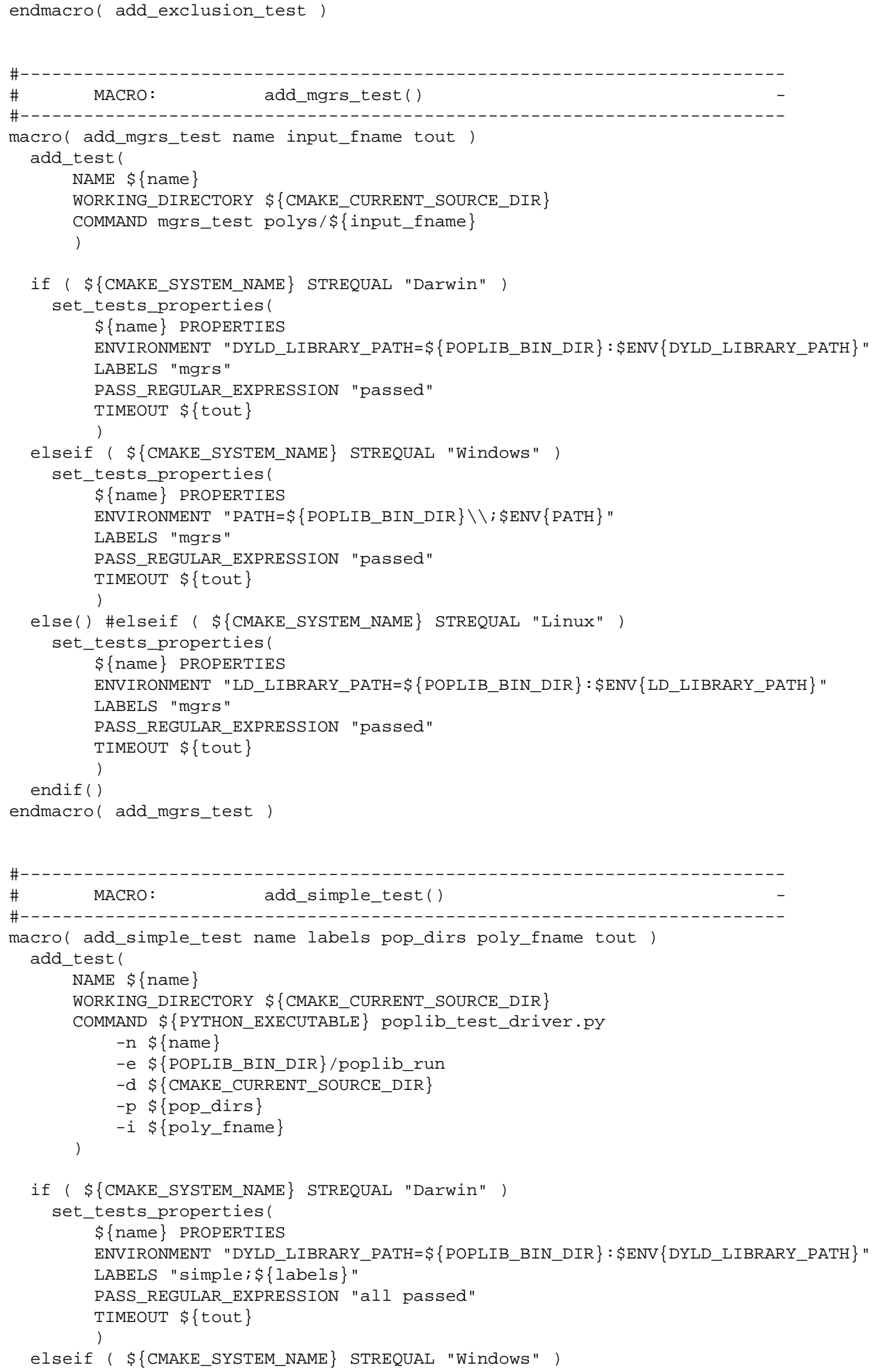




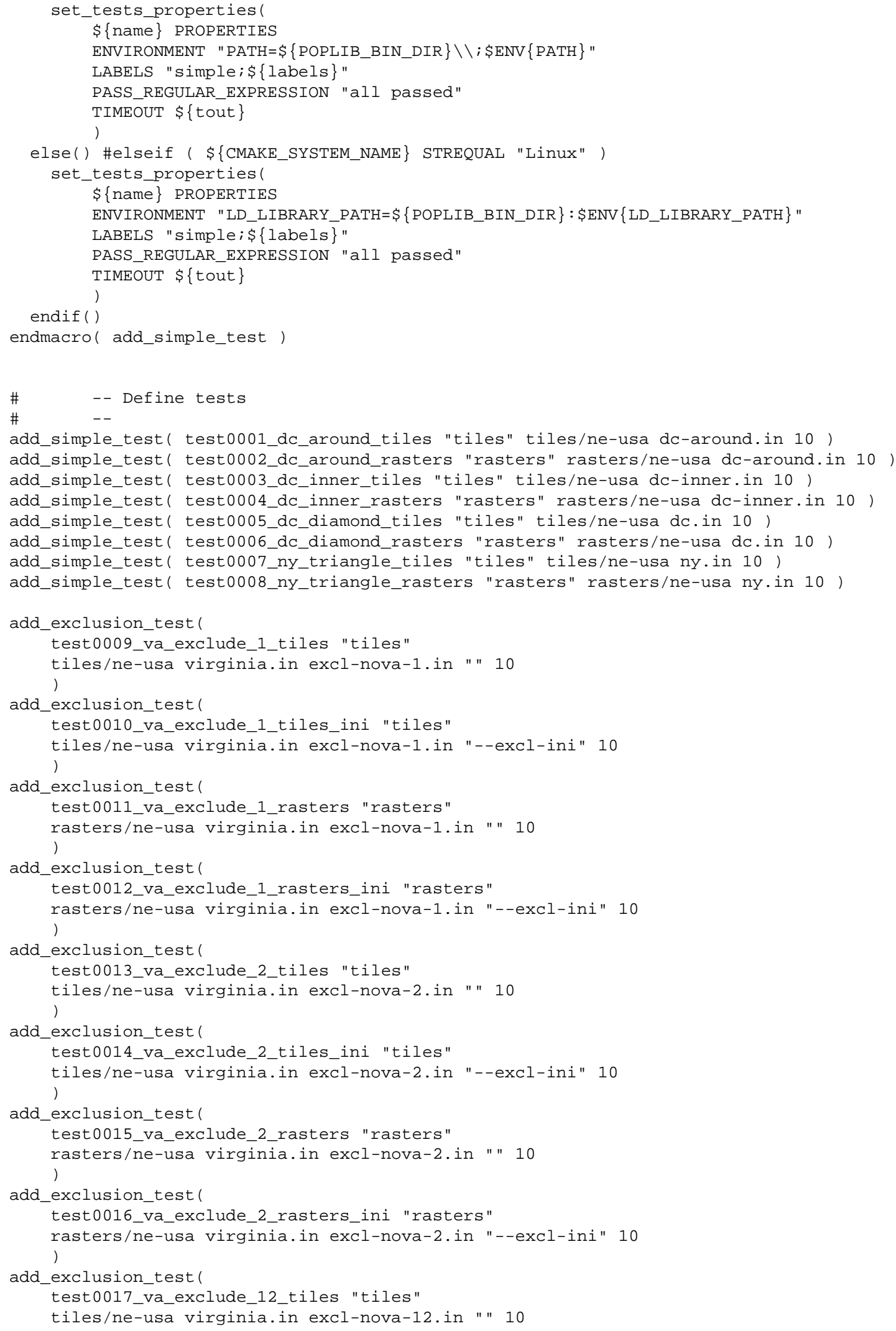


)

add_exclusion_test (

test0018_va_exclude_12_tiles_ini "tiles"

tiles/ne-usa virginia.in excl-nova-12.in "--excl-ini" 10

)

add_exclusion_test(

test0019_va_exclude_12_rasters "rasters"

rasters/ne-usa virginia.in excl-nova-12.in " " 10

)

add_exclusion_test (

test0020_va_exclude_12_rasters_ini "rasters"

rasters/ne-usa virginia.in excl-nova-12.in "--excl-ini" 10

)

add_exclusion_test(

test0021_va_exclude_1n_tiles "tiles"

tiles/ne-usa virginia.in excl-nova-1n.in " " 10

)

add_exclusion_test (

test0022_va_exclude_1n_tiles_ini "tiles"

tiles/ne-usa virginia.in excl-nova-1n.in "--excl-ini" 10

)

add_exclusion_test (

test0023_va_exclude_1n_rasters "rasters"

rasters/ne-usa virginia.in excl-nova-1n.in " " 10

)

add_exclusion_test(

test0024_va_exclude_1n_rasters_ini "rasters"

rasters/ne-usa virginia.in excl-nova-1n.in "--excl-ini" 10 )

add_exclusion_test (

test0025_va_exclude_2n_tiles "tiles"

tiles/ne-usa virginia.in excl-nova-2n.in " " 10

)

add_exclusion_test (

test0026_va_exclude_2n_tiles_ini "tiles"

tiles/ne-usa virginia.in excl-nova-2n.in "--excl-ini" 10

)

add_exclusion_test (

test0027_va_exclude_2n_rasters "rasters"

rasters/ne-usa virginia.in excl-nova-2n.in " 10

)

add_exclusion_test (

test0028_va_exclude_2n_rasters_ini "rasters"

rasters/ne-usa virginia.in excl-nova-2n.in "--excl-ini" 10

)

add_exclusion_test (

test0029_va_exclude_12n_tiles "tiles"

tiles/ne-usa virginia.in excl-nova-12n.in " " 10

)

add_exclusion_test (

test0030_va_exclude_12n_tiles_ini "tiles"

tiles/ne-usa virginia.in excl-nova-12n.in "--excl-ini" 10

)

add_exclusion_test(

test0031_va_exclude_12n_rasters "rasters"

rasters/ne-usa virginia.in excl-nova-12n.in " " 10

)

add_exclusion_test(

test0032_va_exclude_12n_rasters_ini "rasters"

rasters/ne-usa virginia.in excl-nova-12n.in "--excl-ini" 10

)

add_simple_test ( test0033_i285_tiles "tiles" tiles/ne-usa i-285.in 10 )

add_simple_test( test0034_i285_rasters "rasters" rasters/ne-usa i-285.in 10 ) 


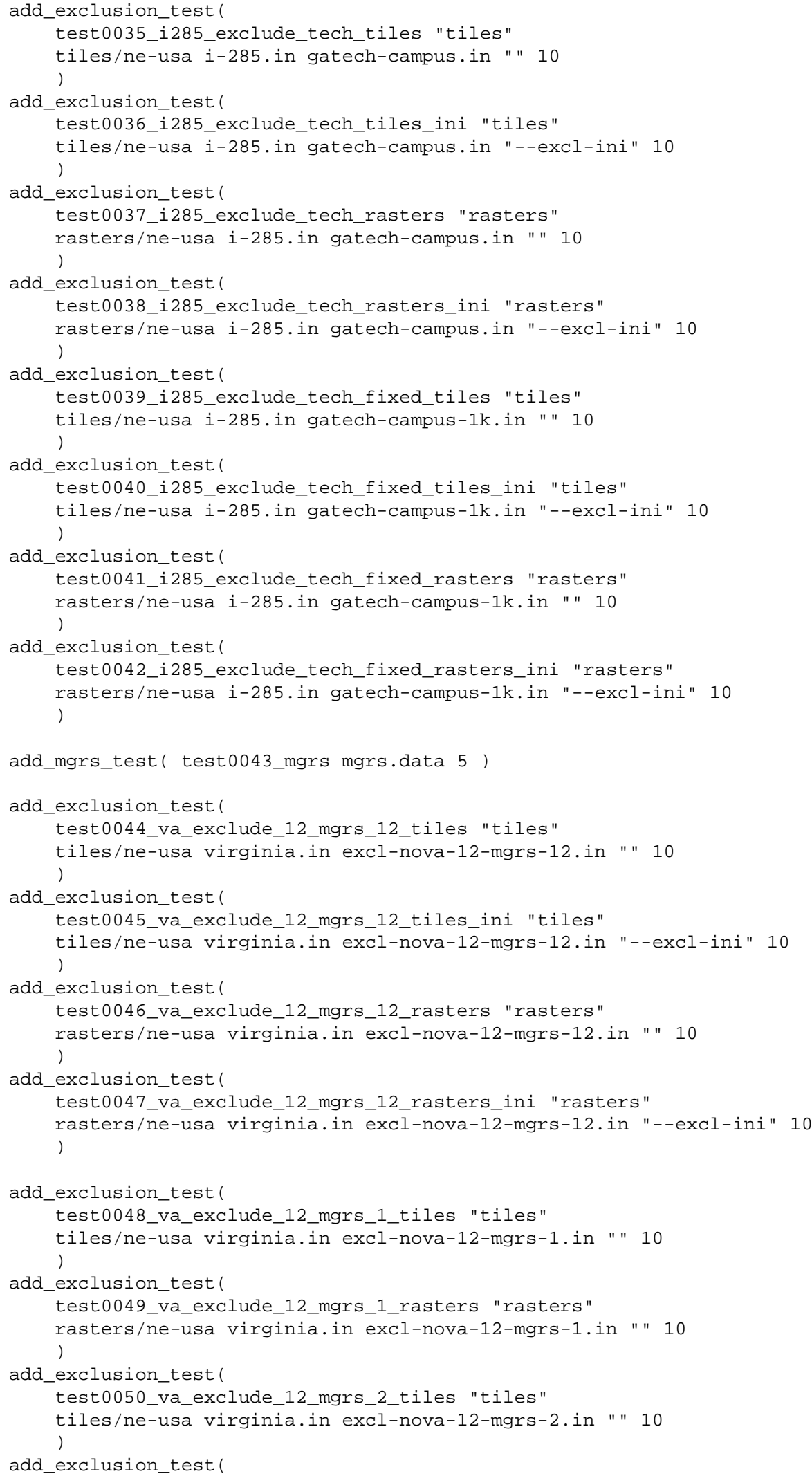


test0051_va_exclude_12_mgrs_2_rasters "rasters"

rasters/ne-usa virginia.in excl-nova-12-mgrs-2.in " " 10

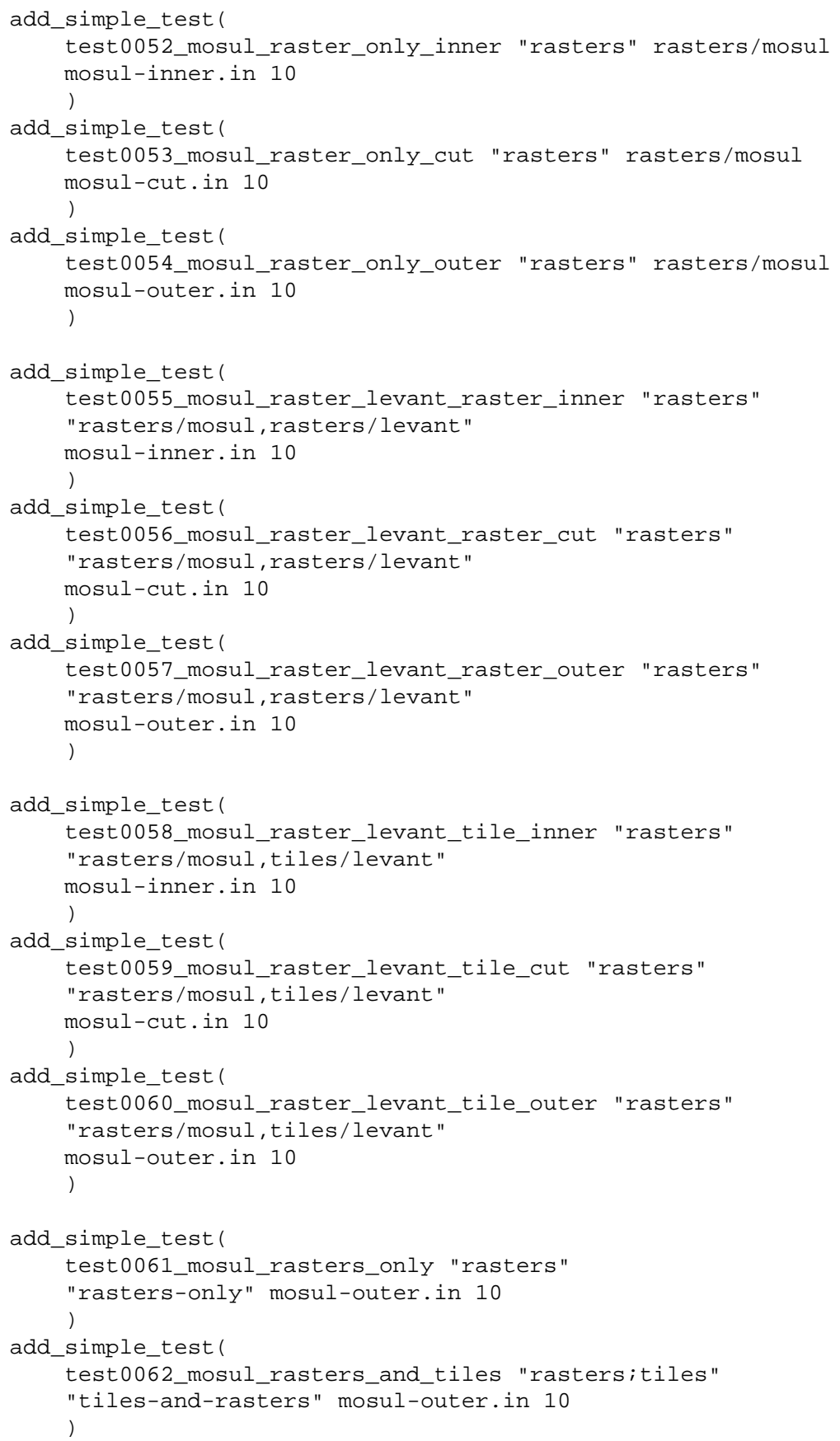


ORNL/TM-2017/145

\section{INTERNAL DISTRIBUTION}

1. R. W. Lee

2. C. D. Sulfredge

3. ORNL Office of Technical Information and Classification

\section{EXTERNAL DISTRIBUTION}

4. Todd Hann, Chief, Hazards \& Effects Modeling Division, Information Sciences \& Applications Department, Defense Threat Reduction Agency, 8725 John J. Kingman Rd., Stop 6201, Ft Belvoir, VA 22060-6201 